\title{
BMJ Global Health Health and well-being of rotation workers in the mining, offshore oil and gas, and construction industry: a systematic review
}

To cite: Asare BY-A

Kwasnicka D, Powell D, et al. Health and well-being of rotation workers in the mining, offshore oil and gas, and construction industry: a systematic review. BMJ Global Health 2021;6:e005112. doi:10.1136/ bmjgh-2021-005112

Handling editor Seye Abimbola

- Additional supplemental material is published online only. To view, please visit the journal online (http://dx.doi.org/10. 1136/bmjgh-2021-005112)

Received 22 January 2021 Accepted 24 June 2021

\section{Check for updates}

(c) Author(s) (or their employer(s)) 2021. Re-use permitted under CC BY-NC. No commercial re-use. See rights and permissions. Published by BMJ.

For numbered affiliations see end of article.

\section{Correspondence to}

Bernard Yeboah-Asiamah Asare; bernard.yeboah-asiamah@ postgrad.curtin.edu.au

\section{ABSTRACT}

Introduction Rotation work, characterised by travelling long distances to work in isolated areas where workers typically rotate consecutive days working and living on-site with periods at home, is increasingly used in the resources and construction sectors globally. Such employment practices may have an impact on workers' health and well-being. This systematic review explores the impact rotation work has on mental and physical outcomes in rotation workers in the resources and construction sectors.

Method The PubMed, Medline, EMBASE, CINAHL, PsycINF0, and Scopus databases were systematically searched on 1 May 2020 to identify quantitative, qualitative and mixed-method studies addressing the health of rotation workers published in peer-reviewed journals. Findings from the studies were summarised narratively.

Results Of 6268 studies retrieved, 90 studies were included in the review. Studies suggested higher prevalence of psychological distress in onshore rotation workers and higher overweight/obesity rates among rotation workers as compared with the general population. We found more sleep problems and higher levels of smoking during work periods compared with off-site days; and higher alcohol intake during off-site days compared with on-site days. Workers generally perceived their physical health status as good. High-perceived job demands (such as workload, repetitive work) were associated with mental distress and exhaustion, sleep problems and perceived poor physical health status, while high-perceived job resources (such as job clarity/control, support) were associated with low mental distress and exhaustion, less smoking and alcohol intake, and better sleep.

Conclusion Rotation work is associated with several poorer health behaviours and outcomes, such as sleep problems, smoking, alcohol consumption and overweight/ obesity. Interventions needed to improve rotation workers' health should include maximising available job resources and reducing job demands. Further longitudinal studies are needed to explore the long-term health effects of rotation work and the short-term contextual effects of the different aspects of rotation work.

\section{Key questions}

What is already known?

- Rotation work arrangements of rotating consecutive days of working and living on-site with periods at home are increasingly used in the resources and construction sectors around the world.

- Rotation employment is associated with severa health and well-being issues among workers.

What are the new findings?

- Prevalence of psychological distress varied between onshore and offshore rotation workers; onshore rotation workers showed higher prevalence than offshore workers and the general population.

- Studies suggested both onshore and offshore rotation workers had poorer sleep and more fatigue during on-shift days; smoked more; consumed more alcohol; and were more overweight and obese than the general population.

- Job demands of rotation work were associated with poor physical and mental health outcomes, while available job resources were associated with better physical and mental health outcomes of workers.

What do the new findings imply?

- Studies are needed to identify the causal determinants of poorer health outcomes in rotation work and investment in interventions to minimise their impact.

- There is a need for creating workplace environments that minimise the negative aspects of rotation work and maximise the positive aspects to support rotation workers to reduce job stress and promote health.

\section{BACKGROUND}

Rotation work is characterised by travelling long distances to work in isolated areas: workers typically rotate consecutive days of working and living on-site with periods at home. ${ }^{1}$ Rotation work is commonly referred to as long distance commuting (LDC) due to the distance between worksite and home, which could be more than 
$100 \mathrm{~km}$. Other terms used to describe this type of work are: fly-in fly-out (FIFO), drive-in drive-out (DIDO) or bus-in busout (BIBO) or ship-in ship-out (SISO) based on the means of transport used. ${ }^{2}{ }^{3}$ Rotation work differs from other mobile work arrangements by its 'rotational work schedule' of prespecified consecutive days of work followed by leave periods, known as roster systems, which vary and can be even or uneven periods; for example, 2 weeks' work/2 weeks' home, or 8 days' work/ 6 days' home. ${ }^{4}$ Other typical characteristics of rotation work are: extended working hours ranging between 10 and 14 hours ${ }^{5}$ with average 12 hours per shift considered as standard ${ }^{36}$; provision of accommodation at or near the worksite; living without families; and transportation arrangements between the worksite and home, commonly paid for or subsidised by companies. ${ }^{13}$ Working days are compressed into day and/or night shift patterns described as fixed/regular day shift or night shift and irregular/swing/rotational shift of day and night. ${ }^{6}$

Rotation work is increasingly practised around the world in the resources sector, originally in offshore oil and gas sector $^{25}$ where daily commuting is practically impossible ${ }^{3}$ and, more recently, within onshore mining and related construction sectors, particularly in Australia and Canada. ${ }^{27}$ Rotation work is increasingly used as a result of resources boom leading to high demand for skilled labour; to staff operations in remote areas where labour is in shortage ${ }^{1378}$; and as ways of moving workers during construction phases and between short-life extraction sites ${ }^{8}$ and cutting down the cost associated with developing, maintaining and decommissioning of 'single-industry communities' ${ }^{5} 8$ Furthermore, increasing use of rotation work in the onshore mining and related construction sectors has also been attributed to the lack of social amenities at remote communities preventing families from relocating nearby, ${ }^{38}$ and the improved flexible and low-cost transportation and communication systems. ${ }^{18}$

However, the employment practices of workers differ between onshore sites and offshore installations. Offshore workers are mostly on more extended rosters; for example, typically 2 weeks on/ 2 or 3 weeks off in the $\mathrm{UK}^{9}$ or 4 weeks on $/ 4$ weeks off in China ${ }^{10}$ and work overtime (averaging more than 16 hours per week), ${ }^{11}$ whereas onshore mining and construction-related sites mostly work shorter and asymmetric rosters ${ }^{12}$; for example, 8 days on/6 days off in Australia. ${ }^{13} 14$ Offshore rotation workers typically share their on-site accommodation with another worker, leisure activities and facilities are normally confined to the worksites (with limited space, reduced illumination and aeration $)^{915}$ and are exposed to varying weather conditions such as strong wind and cold. $^{6}{ }^{16}$ Onshore rotation workers have typically not shared on-site accommodation, recreational facilities are often not confined and could be nearby worksites, ${ }^{3}$ and workers may be faced with dry and hot temperatures. ${ }^{17}$

Working in a FIFO job usually attracts relatively high salaries with relatively long periods of leave to be with family and friends. ${ }^{8}$ Nevertheless, rotation employment is often associated with several health and well-being issues among workers. ${ }^{48}$ A narrative review of 26 studies has documented high levels of occupational stress, poor mental well-being, high body mass index (BMI, overweight and obese), musculoskeletal disorders, poor diet, limited physical activity, and high rates of smoking and alcohol intake in offshore oil and gas workers. ${ }^{19}$ Another review of 59 studies to examine the impact of FIFO work on mental health and well-being highlighted higher levels of mental health problems among FIFO workers (mostly onshore) compared with the general population in Australia. ${ }^{14}$ Another review highlighted sleep disruptions and accumulated fatigue among rotation workers. ${ }^{4}$ The high risk of health problems among rotation workers has been associated with rotation work characteristics ${ }^{4}$ including long work hours and shift patterns, ${ }^{6}$ demanding workload or task, and occupational and environmental stressors, ${ }^{6}$ such as the lack of social support from supervisors and work colleagues. ${ }^{19}$ Two reviews that focused on offshore oil and gas workers ${ }^{6}{ }^{20}$ found offshore night shift workers experienced more sleep problems than day shift workers, and that adaption to night work was faster than re-adaption to daytime work or at home. In the review by Parkes ${ }^{6}{ }^{6}$ offshore shift patterns were found to be associated with gastric complaints and impaired mental health. The research outlined suggests several possible psychosocial and health effects associated with rotation work. Although previous systematic reviews have highlighted the health impact of rotation work on workers, these reviews have focused on the effects of shift pattern arrangement on specific health outcomes, ${ }^{620}$ general health issues, ${ }^{19}{ }^{21}$ and impact on mental health and well-being. ${ }^{14}$ Meanwhile, these reviews were limited to specific working populations in the resource industry (eg, offshore oil and gas workers), ${ }^{6}{ }^{19-21}$ and specific geographical setting (eg, Australia and the North Sea, UK). ${ }^{614}$ This current systematic review covers all the occupational populations in the resource (mining and offshore oil/gas) and construction sectors and is not limited to any geographical setting or specific health condition, to give a broad overview of the health impact of rotation work globally.

The objectives of this review are to synthesise: (1) the reported physical and mental health outcomes and health-related behaviours of rotation workers in the resource and construction sectors, and (2) work-related factors associated with the physical and mental health and health-related behaviours of the rotation workers.

\section{METHOD}

\section{Study design}

This study is a narrative systematic review of literature conducted following the guidelines of Joanna Briggs Institute (JBI) for quantitative and qualitative reviews ${ }^{22}$ and reported in line with the Preferred Reporting Items for Systematic Reviews and Meta-Analyses guidelines. ${ }^{23}$ The protocol of this review was preregistered on PROSPERO (ID=CRD42020167649).

\section{Eligibility criteria}

The review included quantitative, qualitative and mixed-method studies, original articles published in 
peer-reviewed journals and in English language. The review included studies with participants who were rotation workers or LDC, or FIFO or DIDO or BIBO or SISO and worked in the resource (offshore oil and gas, and mining) and construction industry. Rotation workers were defined as those who travel long distances to work in remote areas, operate long work hours (mostly for 12 hours) and work shift patterns for a specified number of days, and after which they come back home to spend another specified number of days. Studies which drew data from rotation workers, comparing them with other groups, were included. Studies with more than $50 \%$ of participants classified as LDC, DIDO, FIFO, BIBO and SISO workers in the resources (mining and oil and gas) were also included.

Quantitative studies were included in the review if they measured and reported physical and mental health outcomes, health-related behaviours and/or work-related factors associated with health outcomes among rotation workers. Qualitative studies that discussed the impact of rotation work arrangement on the physical and mental health and well-being of rotation workers and the perception of the rotation work characteristics that influence their health and well-being were also included.

We excluded studies that were reviews, research reports, editorials, book chapters, letters, conference proceedings, laboratory studies, and study design not clearly defined, or used proxy data (medical records or administrative data) as opposed to recruited participants' data. Studies that reported on adaption and re-adaption of circadian rhythm, and cancers were excluded. The quantitative or qualitative components of mixed-method studies which do not report on participants' characteristics, data collection and analysis methods were excluded.

\section{Data sources and search procedure}

Six electronic databases including PubMed, Medline, EMBASE, CINAHL, PsycINFO, and Scopus were searched for peer-reviewed relevant publications with no restrictions on study designs, date of publication and geographical location. The search strategy used included two groups of terms related to health and rotation work. Health included search terms such as sleep, anxiety, depression, stress, fatigue, alcohol, smoking, "physical activity", exercise, overweight, obesity, "body mass index", diet, "mental health", "psychological distress", "physical health", sick*, ill*, wellbeing. Rotation work included search terms such as "Fly-in fly-out", FIFO, "long-distance commuting", "rotation shift", "rotation work shift", "Drive-in Drive-out", offshore. The two main groups of terms were combined with 'AND' and the search terms within each group were combined with 'OR'. Full search strategy including key terms and subject headings for each of the databases used is presented in online supplemental material 1. Hand searching for other relevant articles was done by reviewing the reference list of the included articles. Searches were conducted on 1 May 2020.

\section{Study screening and selection}

The citations identified were uploaded into EndNote and later to the Covidencesoftware ${ }^{24}$ and all duplicates removed. Two of the authors (BY-AA and DK) then screened the titles and abstracts of articles for eligibility. Full texts for all potential eligible studies were retrieved and screened again for eligibility against the inclusion criteria. Differences that arose were resolved through discussion, and suitable articles were included in the systematic review. Articles excluded at the full-text screening were recorded and the reasons that informed the exclusion of studies per the inclusion criteria reported (figure 1).

\section{Assessment of methodological quality}

The articles included in the review were evaluated for methodological quality independently by two of the reviewers (BY-AA and DK). The tools for appraisal of quantitative descriptive studies in the JBI Meta-Analysis of Statistics Assessment and Review Instrument (JBI-MASt ARI) and JBI Qualitative Assessment and Review Instrument (JBI-QARI) ${ }^{25}$ were respectively used to assess the quantitative and qualitative studies included in the review. Issues of any differences that arose were resolved through discussion. Each tool has a checklist of items rated on 'Yes', 'No', 'Unclear' and 'Not applicable' and was assigned with a score of 1 for 'Yes', 0 for 'No' and 'Unclear', and not applicable items were excluded from the scoring. Studies were rated against the items on the checklists; tools for analytical cross-sectional and cohort studies included 9-11 items with possible scores between 0 and 11, while the tool for qualitative study assessment included 10 items and a study score ranged between 0 and 10 . Scores were subsequently converted to give a percentage score $^{26}$ with scores below $50 \%$ considered low quality, $50 \%-69 \%$ considered medium quality, and scores above $70 \%$ representing high quality. The quality assessment was not used to exclude studies from the review ${ }^{27}$ and as stipulated by Lucas $e t a t^{8}$ strictly using quality criteria for exclusion may exclude relevant studies based on not conforming with a specific reporting criterion. The quality assessment results were recorded and reported in the review to inform the interpretation of the findings.

\section{Data extraction and strategy for data synthesis and analysis}

Standardised data extraction sheets (online supplemental material 2) were developed based on the templates from the JBI-MASt ARI data extraction tool for quantitative data and JBI-QARI for the qualitative studies and piloted specifically for this study and were used to extract data from selected studies. For quantitative studies, the key information extracted included authors, year of publication, study design, aims/objectives, study setting and participants' characteristics, health outcomes and their mode of measurements, and the key findings. For qualitative studies, together with the study characteristics, perceptions of the physical and mental well-being and work-related characteristics that influence their wellbeing were extracted. One reviewer (BY-AA) did data extraction and another researcher (DK) cross-checked 


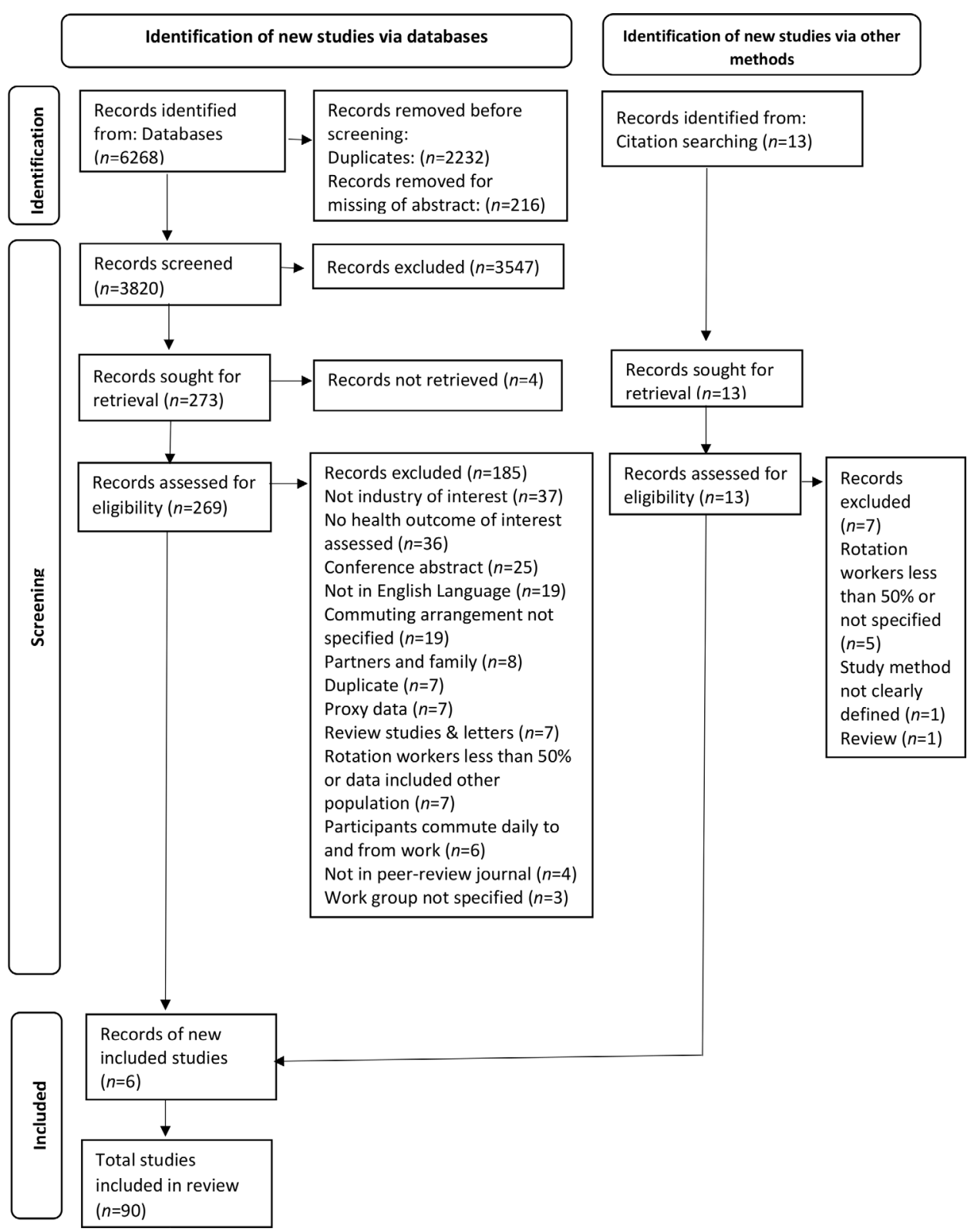

Figure 1 Flow diagram of identifying and selecting studies for the systematic review.

$10 \%$ of data. Any differences that arose were resolved through discussion.

Quantitative and qualitative data were extracted in terms of the studies' characteristics and key findings and table summaries were presented. The review aimed to explore health outcomes and related behaviours reported among rotation workers, and as such thematic analysis was done. Based on previous literature, ${ }^{46141920}$ we expected that studies would fit into four broad themes: mental health outcomes, physical health outcomes, sleep and broadly defined 'lifestyle' behaviours. Studies were narratively reviewed within these themes and further organised into subthemes as they emerged from the reviewed literature. Meta-analysis was not performed due to the high heterogeneity of study designs and assessment of health outcomes. We report effect sizes in text where this was possible to do so briefly and meaningfully (for example, standardised effect sizes were reported) and further methodological and statistical details can be found in online supplemental material 3.

\section{Patient and public involvement}

Patients and the public were not involved in this systematic review.

\section{RESULTS}

\section{Characteristics of studies}

The initial searches retrieved 6268 studies, of which 269 full texts were screened for eligibility, and 90 studies $(76$ quantitative, 10 qualitative and 4 mixed-method studies) were included in the review (figure 1). Included studies (online supplemental material 3), published between 1987 and 2020, were conducted in several countries 
around the world: 25 in the UK, 23 each in Australia and Norway, 6 in China, 3 in Iran, 4 in the Netherlands, 2 in Brazil, and 1 each in Sweden, the USA, Croatia and Canada. Forty-two of the studies examined outcome data on mental health and well-being, 38 studies on sleep problems and fatigue, 20 on BMI, 15 on perceived physical health status, and 14 studies each on alcohol intake and smoking, 11 each on physical activity and musculoskeletal disorders, 7 on diet/nutrition and 6 on gastric problems.

The majority of studies $(n=64)$ were conducted with offshore oil and gas workers, 16 studies with mining workers, 5 with FIFO workers predominately from mining sectors, 3 with construction rotation workers, 1 with onshore oil workers, and 1 with mining and construction workers. The majority of participants in the studies were men (averagely 91.2\%), and all were aged between 16 and 68 years (mean of study means $=39.23 \pm 4.29$ years). The majority $(89.25 \%)$ of studies were rated medium to high on the JBI Quality Rating Scale: 58 of 90 studies, for example, ${ }^{29-43}$ rated $\geq 70 \%$ (high), 23 studies, for example ${ }^{1844-49}$ rated 50\%-69\% (medium), and 9 studies, for example, ${ }^{1750-57}$ rated $<50 \%$ (low) (table 1 ).

Based on their findings, studies were categorised into four main themes of health outcomes and related behaviours: (1) mental health and well-being, (2) physical health, (3) sleep and (4) lifestyle behaviours. Below, findings for each theme are summarised in terms of outcomes and predictors for each theme.

\section{Mental health and well-being}

Psychological distress

Studies examined prevalence using cut-offs on validated scales. Prevalence rates of psychological distress varied across eight studies: onshore workers $(10.0 \%-36.3 \%$, $\mathrm{n}=6$ studies) ${ }^{18} 435258-60$ and offshore workers $(8.0 \%$ $14.0 \%, \mathrm{n}=2$ studies). ${ }^{61}{ }^{62}$ No study recruited a general population comparison group, only comparing these rates with secondary data sources reflecting the general population (typically ranging from $7.6 \%$ to $13 \%$ ) in five studies. ${ }^{43} 52596062$

\section{Depression}

Studies showed mixed findings for depression and depressive symptoms in rotation workers. Studies employed a mixture of methods to identify cases of depression within rotation workers, including cut-offs on validated scales $^{184142506364}$ and symptoms checklist. ${ }^{58} 65-67$ Six studies examined the prevalence of depression among rotation workers: onshore workers $(28.3 \%-32.3 \%, \mathrm{n}=3$ studies $)^{18} 41 \quad 42$; offshore workers $(16.7 \%-28.0 \%, \mathrm{n}=3$ studies). ${ }^{506364}$ No general population comparison groups were recruited in any study, though two studies ${ }^{41} 42$ made reference to a secondary source ${ }^{68}$ reporting prevalence of depressive episodes $(4.1 \%)$ and affective disorders (6.2\%) in Australia. One study recruited both offshore rotation workers $(16.7 \%$ prevalence) and onshore non-rotation petroleum workers $(22.8 \%)$, but statistical comparisons were not performed. ${ }^{64}$

Seven studies examined the levels of depressive symptoms among rotation workers using symptoms checklist. ${ }^{1842505865-67}$ Using the cut-offs belonging to the scales used, the sample means suggested that, on average, rotation workers had minimal depressive symptoms in four studies (one offshore, three onshore) ${ }^{5865-67}$ and moderate in one study. ${ }^{18}$ Two studies with a comparison group compared fathers with onshore rotation jobs with other fathers in cross-sectional surveys, but the difference was not statistically significant. ${ }^{667}$ Two other studies with comparison group compared rotation workers with onshore non-rotation workers and found depressive symptoms to be statistically significantly lower in rotation workers in one study (marginal mean scores 15.5; 95\% $\mathrm{CI}=14.3$ to 16.6 vs $19.7 ; 95 \% \mathrm{CI}=17.0$ to $22.4, \mathrm{p}=0.01)^{42}$ but no differences in the other study. ${ }^{50}$

\section{Anxiety}

Studies regarding anxiety among rotation workers also showed mixed findings. Studies employed a mixture of methods to identify cases of anxiety within rotation workers using cut-offs on validated scales ${ }^{18506364}$ and symptoms checklist. ${ }^{58676970}$ Four studies examined the prevalence of anxiety among rotation workers ${ }^{18} 506364$ : $22.3 \%$ among onshore rotation workers ${ }^{18}$ and $11.4 \%-$ $15 \%$ among offshore rotation workers. ${ }^{506364}$ Only one study recruited and compared offshore rotation workers (11.4\% prevalence) with onshore non-rotation petroleum workers $(13.9 \%)$, but statistical comparisons were not performed. ${ }^{64}$

Furthermore, nine studies examined the level of anxiety symptoms among rotation workers using symptoms checklist. $^{5058666769-73}$ Of these studies, seven reported low level of anxiety symptoms: one study described their samples as having low levels of anxiety symptoms based on their sample means being below some threshold on the scale used ${ }^{58}$ and remaining studies also reported sample means below any threshold for normal/mild anxiety. ${ }^{66} 676971-73$

No study recruited a general population comparison group, only comparing the mean scores with secondary data sources and reported comparable scores among onshore rotation workers in one study ${ }^{58}$ but higher scores among offshore rotation workers in another study. ${ }^{70}$ Four studies with comparison groups compared rotation jobs with non-rotation workers in cross-sectional surveys: one study found offshore rotation had higher level of anxiety symptoms than onshore non-rotation petroleum workers $(3.62 \pm 3.42$ vs $2.43 \pm 2.18, \mathrm{p}<0.01),{ }^{69}$ but no statistically significant differences were reported in three studies. 506667

\section{Stress}

Six studies examined levels of stress symptoms among rotation workers using symptoms checklist. ${ }^{18} 3058666774$ Using the cut-offs and scores based on scales used, the 


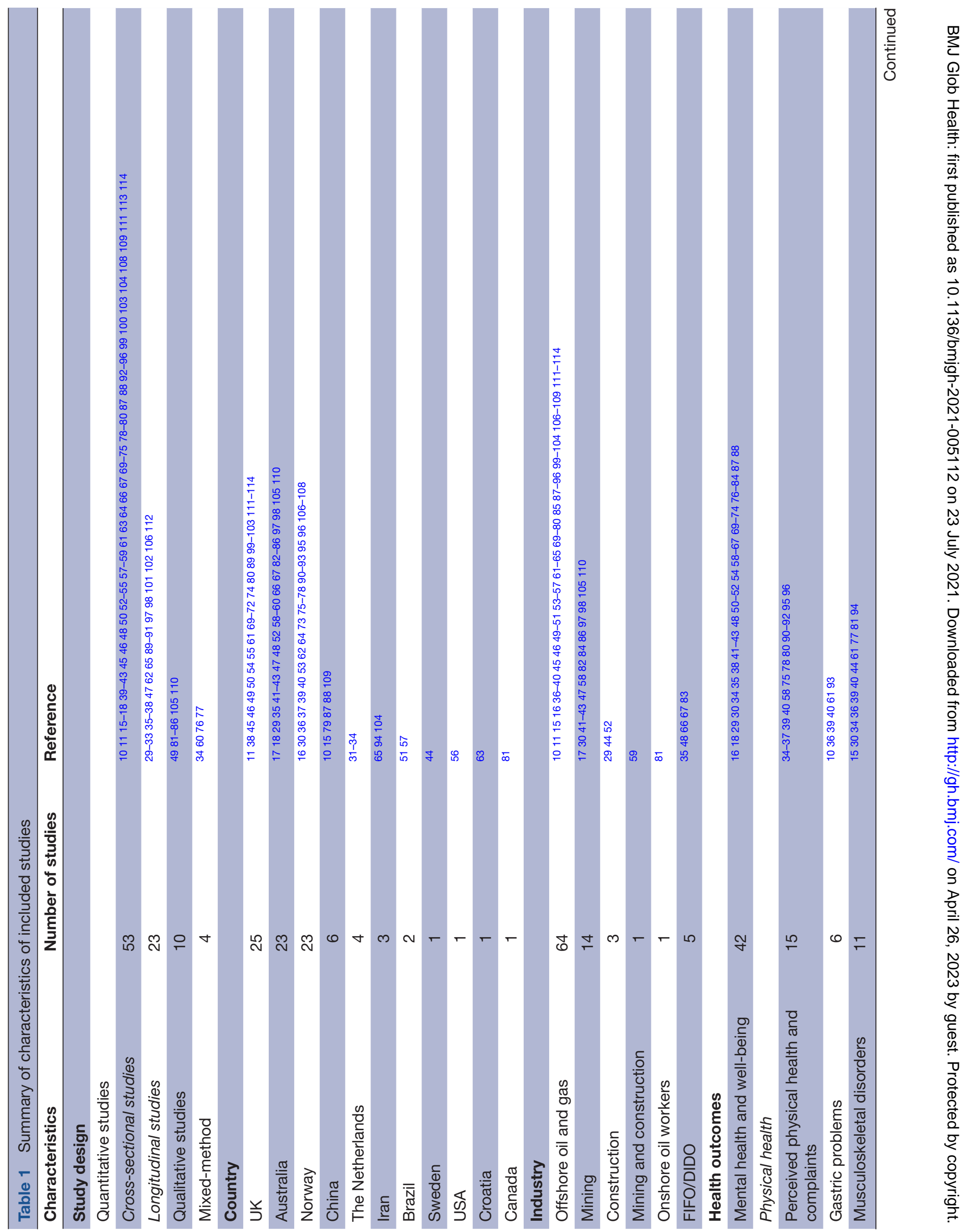




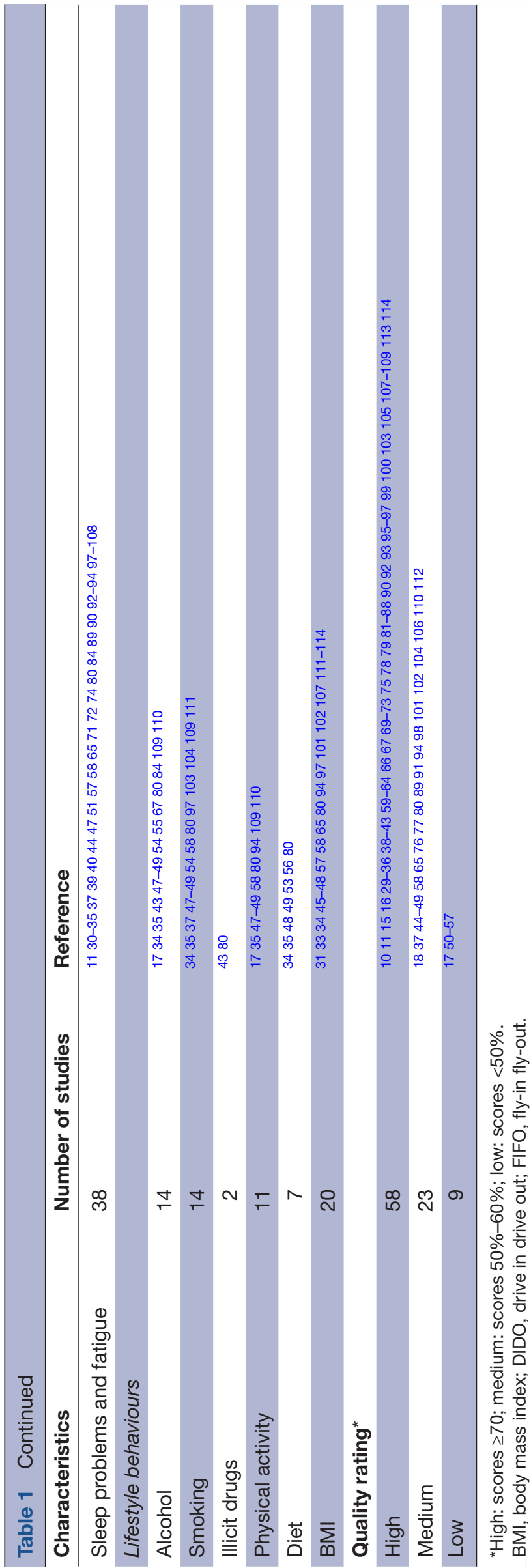

sample means suggested rotation workers had low level of stress symptoms in five studies ${ }^{18} 30586774$ and moderate in one study. ${ }^{66}$ Two cross-sectional studies with comparison groups compared fathers working onshore rotation jobs with fathers working non-rotation jobs, but the differences were not statistically significant. ${ }^{66}{ }^{67}$ No study recruited a general population comparison group, one study only compared mean scores on Depression, Anxiety and Stress-21 Scale with secondary data sources in nonclinical general population and reported comparable scores among onshore rotation workers, but no statistical comparison was done. ${ }^{58}$

\section{Emotional exhaustion and worn-out}

Four studies examined emotional exhaustion and feeling 'worn-out' among rotation workers using symptoms checklist. ${ }^{29}{ }^{75-77}$ Both emotional exhaustion and 'worn-out', defined by 'symptoms of emotional liability, tiredness and cognitive confusion', have been operationalised by the same Worn-out Scale from the General Well-Being Questionnaire. ${ }^{75-77}$ Based on the mean scores and cut-offs of scales used, the sample means suggested rotation workers had low emotional exhaustion and low 'worn-out' in three studies. ${ }^{75-77}$ One longitudinal study documented a daily increase in emotional exhaustion and decrease in work engagement over the course of up to 28-day onshore rotation work period, but there was no comparison group. ${ }^{29}$ Only one study with a comparison group compared offshore rotation workers with onshore non-rotation petroleum workers, and found statistically lower worn-out level than in onshore non-rotation oil workers (mean score 13.82 vs $15.11, \mathrm{p}<0.001$ ). ${ }^{76}$ No study recruited general population comparison group, two studies only compared mean scores with secondary data sources in factory workers and reported comparable scores among offshore rotation workers, but no statistical comparison was done. ${ }^{7677}$ Qualitative evidence suggested offshore rotation workers experienced mental exhaustion due to the long shift hours associated with rotation work. ${ }^{34}$

\section{Suicide risk}

Only two studies examined suicide risk among rotation workers, and both used the same sample (onshore rotation workers in Australia). In these studies, suicide risk was determined using Beck Hopelessness Scale, with scores above 9 indicating elevated risk for suicide intentions and behaviour. Here, suicide risk prevalence was reported as $26.7 \% .{ }^{41} 42$ One of these studies found suicide risk was lower among onshore rotation mining workers (26.7\% prevalence) than onshore non-rotation mining workers $(27.4 \%)(p=0.02) .{ }^{42}$ No general population comparison groups were recruited, though both studies made reference to a secondary source reporting prevalence of one in six of the general population. ${ }^{41} 42$ There was no study that examined suicide intention or behaviour among offshore rotation workers. 


\section{Psychological well-being}

Studies showed inconsistent findings. Studies employed a mixture of methods to examine the levels of psychological well-being within rotation workers using symptoms checklist, ${ }^{54} 69707879$ cut-off points on validated scales $^{3480}$ and self-reported diagnosis of mental health problems. ${ }^{35} 48$ Sample mean scores suggested good mental well-being among offshore rotation workers in three cross-sectional studies ${ }^{69} 7879$ and a daily diary study also reported low daily use of medication for mental health problems among onshore rotation workers across on-shift and off-shift days. ${ }^{35}$

Five studies compared psychological well-being of rotation workers with other work group. ${ }^{485469} 7078$ Three of the studies with comparison group compared rotation workers with non-rotation workers and found prevalence of mental health problems to be statistically significantly lower in rotation workers in one study $(7.7 \% ; 95 \%$ $\mathrm{CI}=4.4 \%$ to $11.0 \%$ vs $13.0 \%$; $95 \% \mathrm{CI}=12.1 \%$ to $13.9 \%$, $\mathrm{p}<0.01),{ }^{48}$ higher mean scores (ie, high levels of poor mental health symptoms) among rotation workers in one study $(8.75 \pm 3.76$ vs $7.64 \pm 2.94 ; \mathrm{p}<0.05),{ }^{69}$ but comparable psychological health complaints in the other study (no statistical analysis was done) ${ }^{78}$ Two studies did not recruit comparison group, but compared sample mean scores with secondary data source in non-rotation industrial workers and reported comparable levels of mental health well-being among offshore rotation workers, but no statistical comparisons were done ${ }^{5470}$ No study recruited a general population comparison group, two studies compared mean scores with secondary data sources and reported higher mental functioning and mental wellbeing in offshore rotation workers than in the normative population, ${ }^{3480}$ but no statistical comparisons were done.

Similarly, qualitative evidence was also mixed. Eight qualitative studies reported that onshore rotation workers experience high mental distress due to the demands and challenges of rotation work lifestyle ${ }^{345181-86}$; for instance experiencing isolation and loneliness, ${ }^{83} 85$ work-home conflicts, ${ }^{34}{ }^{81-83}$ family and social disruptions, ${ }^{81}$ 83-85 worries of delegating house chores to partners ${ }^{83} 84$ and 'pre-boarding stress syndrome' characterised by symptoms including anxiety and bad mood in the last days of leave periods. ${ }^{51}$ However, four of the qualitative studies also reported onshore rotation workers expressed job and life satisfaction with their work, highlighting financial rewards, enough quality time to spend with family/ friends on leave periods, freedom from home stressors/ chores and less effect on their mood. ${ }^{3483-85}$

\section{Predictors of mental health outcomes}

Job demands

Five studies showed high job demands were associated with poor mental health outcomes. ${ }^{16} 2959647687$ For instance, one cross-sectional study reported increase in job demands was associated with increased level of mental distress. ${ }^{64}$ Bowers et al in another cross-sectional study also found workers who were stressed by job tasks were more likely to experience higher mental distress than those who were not stressed at all by their job task $(\mathrm{OR}=6.2 ; 95 \% \mathrm{CI}=1.8$ to 21.2$) .{ }^{59} \mathrm{~A}$ daily survey study found that increases in workload and emotional demands were associated with a daily increased level of emotional exhaustion. ${ }^{29}$ Another longitudinal study also found high job demands to be correlated with increased symptoms of work-stress worn-out (indicative of poor well-being) $(\mathrm{r}=-0.382 ; \mathrm{p}<0.001){ }^{76}$

Two cross-sectional studies identified job type/categories as a predictor of psychological health. ${ }^{69} 78$ Parkes $^{69}$ reported working in higher roles such as supervisory or managerial roles was associated with high level of anxiety.

\section{Job control and clarity}

Four studies found significant association between job control/autonomy and better mental health outcomes. $^{29} 647678$ For instance, a daily diary study reported increase in job autonomy was associated with increased levels of engagement. ${ }^{29}$ Further, a crosssectional study found increased in job control was associated with decreased level of mental distress. ${ }^{64}$ Bergh et al in another cross-sectional study found rotation workers' control over their job was also correlated with less workstress worn-out $(\mathrm{r}=-0.472 ; \mathrm{p}<0.001){ }^{76}$

Two cross-sectional studies also found job clarity was associated with better mental health outcomes. ${ }^{6476}$ One study showed increased in job clarity was associated with decreased level of mental distress. ${ }^{64}$ The other study found rotation workers' clarity on their jobs was also correlated with less work-stress worn-out $(\mathrm{r}=-0.415 ; \mathrm{p}<0.001){ }^{76}$

\section{Roster characteristics}

Three cross-sectional studies found significant associations between roster type/length and shift length with mental health. ${ }^{43563}$ One study found that the odds of high psychological distress, defined by a score of $22-50$ on a scale of 10-50, were higher in workers with 2 weeks on $/ 1$ week off roster $(\mathrm{OR}=2.4 ; 95 \% \mathrm{CI}=1.7$ to 3.4 ; $\mathrm{p}<0.001)$ and 1 week on/ 1 week off roster $(\mathrm{OR}=1.6 ; 95 \%$ $\mathrm{CI}=1.00$ to $2.5 ; \mathrm{p}=0.039$ ) compared with a 4 weeks on $/ 1$ weeks off roster. ${ }^{59}$ Another study in offshore workers on long roster cycle found the odds of higher level of anxiety symptoms (defined by a higher score on a scale of 0-21) were higher in those on 56 days on/28 days off than those on 28 days on/28 days off roster cycle $(\mathrm{OR}=1.53$; $95 \% \mathrm{CI}=1.15$ to 2.04$).{ }^{63}$ Additionally, one study found workers who were stressed by the length of their shifts had increased odds of higher psychological distress $(\mathrm{OR}=2.4 ; 95 \% \mathrm{CI}=1.2$ to $5.1 ; \mathrm{p}=0.017)$ than workers who were not. ${ }^{59}$ Another study reported workers on longer shifts ( $>12$ hours) had higher odds of high psychological distress (scores of 22-50 on a scale of $0-50$ ) than those on shorter shifts $(<12$ hours) (OR=1.61; $95 \% \mathrm{CI}=1.17$ to $2.30) .{ }^{43}$ Similarly, evidence from a qualitative study indicated workers experience mental exhaustion following long shift hours. ${ }^{34}$ 


\section{Work-home interference}

Four cross-sectional studies have also established high work-home interference (undesired interaction between work and home domains/roles) was associated with poor mental health outcomes. ${ }^{16387087}$ For instance, Ljosa et al ${ }^{16}$ established that increase in levels of shift work-home interference was associated with increased mental distress among offshore rotation workers. Similarly, one study found that increase in stress from work-home interference was associated with increased poor mental well-being. ${ }^{38}$ Another study also reported that feeling socially isolated while on-site was strongly related to high psychological distress $\left(r^{2}=0.61\right) .^{52}$

Similarly, qualitative evidence showed psychological/ emotional strain due to social life disruptions ${ }^{34}$ 51 $81-84$ : six studies noted many rotation workers had difficulties balancing work and home/social life, leading to social and domestic conflicts, ${ }^{3451} 81-83$ and difficulties in maintaining family and social relationships. ${ }^{818384}$ Another qualitative study indicated absence from family made rotation workers feel isolated and lonely, and the 'physical and psychological distance' caused tension and distrust which put a strain on the relationship with partners. ${ }^{83}$ Three qualitative studies again indicated rotation workers experience the worries of delegating their domestic responsibilities to their partners ${ }^{8384}$ and missing out on family events. $^{348384}$

\section{Financial situation}

Two cross-sectional studies found an association between workers' financial situation and psychological distress. One study found workers experiencing financial stress were more likely to report high psychological distress $(\mathrm{OR}=6.0 ; 95 \% \mathrm{CI}=2.7 \text { to } 13.1)^{59}$ than those who were not stressed at all by their financial situation. Another study also found that working primarily for financial reasons was associated with increased odds of high psychological distress $(\mathrm{OR}=1.34 ; 95 \% \mathrm{CI}=1.12$ to 1.61$){ }^{43}$

Evidence from three qualitative studies also documented that rotation workers' relatively high income had become a source of stress due to a perceived lack of control or autonomy over their work and career, but being forced or 'trapped' into work rotation due to the financial gain. ${ }^{348183}$

\section{Remoteness and living conditions}

A cross-sectional study found workers stressed from the remoteness of the living environment were more likely to have high psychological distress than those who were not $(\mathrm{OR}=3.7 ; 95 \% \mathrm{CI}=1.6$ to 8.6$) .{ }^{59}$ Another cross-sectional study found increase in stress from living in a remote environment (including factors such as sharing accommodation, disturbance in living accommodation and lack of privacy) was associated with increased levels of anxiety and poor mental well-being. ${ }^{70}$

Similarly, qualitative evidence showed that sharing accommodation at work made workers experience stress from the lack of privacy. ${ }^{34}$

\section{Social support}

Five cross-sectional studies found social support was associated with better mental health outcomes. ${ }^{16} 42617688$ For instance, one study documented perceived support from supervisors was associated with lower risk of psychological distress (relative risk $(\mathrm{RR})=0.76 ; 95 \% \mathrm{CI}=0.63$ to 0.92, $\mathrm{p}<0.01) .{ }^{61}$ Likewise another study found increased social support was associated with lower suicidal risk and lower levels of depression. ${ }^{42}$ Similarly, one study found increased in social support was also associated with decreased in worn-out from work-stress $(r=-0.457$; $\mathrm{p}<0.001) .^{76}$

Similarly, two qualitative studies explored ways of improving the mental well-being of rotation workers and discussed the provision of social support. ${ }^{82} 83$ Ebert and Strehlow ${ }^{82}$ further noted the availability of confidential, trustworthy and proactive chaplaincy support on worksite helped break the 'culture of masculinity' or stigma attached to seeking help for health, and effectively promoted the mental health of rotation workers. Workers identified support from employers, colleagues and emotional support from family and other rotation families as ways to improve their mental well-being. ${ }^{83}$

\section{Stigmatisation and bullying}

Five cross-sectional studies identified workplace bullying to be associated with poor mental health outcomes. 4142526273 Two studies documented workers who experienced workplace bullying were more likely to have high levels of suicide risk $(\mathrm{OR}=2.70 ; 95 \% \mathrm{CI}=1.53$ to 4.76$)$, clinical depression $(\mathrm{OR}=2.38 ; 95 \% \mathrm{CI}=1.40$ to $4.05)^{41}$ and psychological distress $(\mathrm{OR}=1.49 ; 95 \% \mathrm{CI}=1.07$ to 2.10$)^{62}$ than those who did not. Likewise, one study found increase in workplace bullying was associated with increased level of anxiety. ${ }^{73}$ Two other studies reported workers stressed by the fear of workplace stigma attached to mental health problems were much more likely to have high/very high mental distress $(\mathrm{OR}=23.5 ; 95 \% \mathrm{CI}=7.5$ to 73.2) than those not stressed at all, ${ }^{59}$ whereas workers with a high perception of the organisation's commitment to mental health were less likely to have high psychological distress than those who had low perceptions $(\mathrm{OR}=0.69$; $95 \% \mathrm{CI}=0.55$ to 0.85$){ }^{43}$

Evidence from two qualitative studies similarly highlighted that onshore rotation workers are faced with workplace stigma attached to mental health ${ }^{83}$ and public stigmatisation of rotation work as being 'dirty' and 'substance misusers', 81 and an underappreciation of how hard rotation work is, which contribute to worse psychological well-being. ${ }^{81} 83$ Furthermore, three qualitative studies reported rotation worksites were characterised by the 'culture of masculinity' which frowns on weakness but upholds hard work, leading to the uptake of behaviours and bullying, and the reluctance to seek help for health and well-being by workers in order to fit in the work environment. 348183 


\section{Leadership style of managers}

Evidence from four studies showed that the leadership style of managers and supervisors is associated with mental health outcomes among workers. ${ }^{59} 626487$ One longitudinal study identified workers exposed to laissezfaire leadership style, style where managers or supervisors are 'passive and avoidant', had higher odds of psychological distress among rotation workers than those who were not exposed $(\mathrm{OR}=1.69 ; 95 \% \mathrm{CI}=1.12$ to 2.54$){ }^{62}$ Similarly, one cross-sectional study reported an increase in the experience of fair and empowering leadership was associated with decreased in mental distress. ${ }^{64}$ Another cross-sectional study identified workers who were stressed by their immediate supervisors had more increased odds of poor mental health $(\mathrm{OR}=4.3$; 95\% CI 1.6 to 11.3$)$ than those who were not stressed at all. ${ }^{59}$ Chen et al in a crosssectional study also identified increase in stress from management problems was associated with increased poor mental health among workers. ${ }^{87}$

\section{Other occupational stressors}

Occupational stressors were identified to significantly predict poor mental health outcomes in five studies. ${ }^{1038} 8789$ One cross-sectional study found increase in risk perception was associated with increased levels of anxiety among offshore rotation workers. ${ }^{73}$ Two other cross-sectional studies found increase in stress from safety concerns was associated with increased poor mental health. ${ }^{38}$ Another cross-sectional study found motion of offshore platforms had a positive relationship with feelings of depression and anxiety. ${ }^{89}$ Additional crosssectional study also identified increased in perceived job dissatisfaction was associated with reduced mental wellbeing. ${ }^{38}$ Another cross-sectional study found workers satisfied with rotation work had less odds of psychological distress $(\mathrm{OR}=0.33 ; 95 \% \mathrm{CI}=0.25$ to 0.43$)$ than workers who were not satisfied. ${ }^{43}$

Job insecurity has also been found to be associated with mental distress. One cross-sectional study reported that rotation workers with increased concerns about job loss were more likely to have high psychological distress $(\mathrm{OR}=3.17 ; 95 \% \mathrm{CI}=1.96$ to 5.16$)$ than those who were not concerned about losing their jobs. ${ }^{43}$

Likewise, evidence from two qualitative studies showed that rotation workers are reluctant to report or seek help for their mental health problems due to the fear of losing their jobs. ${ }^{81} 83$

\section{Physical health and well-being}

\section{Perceived physical health and subjective health complaints}

Studies showed generally good/very good perceived physical health status among rotation workers. Nine studies examined perceived physical health complaints among rotation workers using self-ratings, ${ }^{34} 363739589091$ self-reported use of medication for physical health problems ${ }^{35}$ and score cut-offs. ${ }^{34} 80$ Seven studies reported high proportions $(73.4 \%-88.6 \%)$ of rotation workers perceived their general physical health as good or very good. ${ }^{34} 363739589091$ Additionally, one longitudinal study found low daily use of physical health medication across on-shift days and off-shift days among onshore rotation workers. ${ }^{35}$ No study recruited a general population comparison group, two studies compared mean scores with secondary data sources and reported higher physical health functioning in offshore rotation workers than in the norm-based population, ${ }^{3480}$ but no statistical comparisons were done.

Eight studies examined subjective health complaints among rotation workers using the Subjective Health Complaints Scale, ${ }^{36} 37394062757892$ all within offshore workers. Based on the mean scores on scale used, the sample means suggested low/some subjective health complaints in seven studies. ${ }^{36} 374062757892$ One of these was a longitudinal study, reporting no significant changes in the level of subjective health complaints from the start to the end of a 2-week work period. ${ }^{37}$ However, one crosssectional study reported high prevalence of subjective health complaints based on one or more complaints in the last 30 days among offshore rotation workers, and that was significantly higher among workers with shift work disorder (SWD) (condition of excessive sleepiness and insomnia) than workers without SWD $(100 \%$ vs $89.9 \% ; \mathrm{p}<0.001) .{ }^{39}$

\section{Gastric problems}

Studies examining gastric problems reported mixed findings. Six studies examined gastric problems among rotation workers using symptoms checklist. Two cross-sectional studies documented prevalence (31\%) of general gastric problems including indigestion, heartburns and stomach pains, ${ }^{61}$ and prevalence of poor appetite $(66.8 \%)$ and localised epigastric pain $(52.3 \%)^{10}$ in offshore rotation workers. Another cross-sectional study reported high prevalence of gastrointestinal complaints based on one or more complaints in the last 30 days among offshore rotation workers, and that was significantly higher among workers with SWD than workers without SWD $(87 \%$ vs $50.6 \% ; \mathrm{p}<0.01) .{ }^{39}$ However, based on the mean scores of scales used, sample means suggested in two other crosssectional studies ${ }^{40} 93$ and one longitudinal study, ${ }^{36}$ low scores on complaints of gastric problems (ie, low levels) among offshore rotation workers.

\section{Musculoskeletal disorders}

Ten studies examined musculoskeletal disorders among rotation workers using symptoms checklist and findings were mixed. Seven of these studies reported prevalence of musculoskeletal disorders: among offshore rotation workers $(7.7 \%-56.3 \%)^{1534} 617794$ and onshore rotation workers (ranging from $1 \%$ headache to $5 \%$ pain in the legs). ${ }^{30}$ Another cross-sectional study reported high prevalence of musculoskeletal pain based on one or more complaints in the last 30 days among offshore rotation workers, and that was significantly higher among workers with SWDs than workers without SWDs $(90.9 \%$ vs $69.6 \%$; $\mathrm{p}=0.04) .{ }^{39}$ 
Three other studies, based on the sample mean scores of scales used, reported few subjective musculoskeletal complaints. ${ }^{3640}$ But one of these studies compared musculoskeletal complaints among age groups and reported high levels of musculoskeletal complaints among offshore rotation workers aged above 50 years compared with younger workers $(16.93 \pm 45.19$ vs $1.71 \pm 5.61, \mathrm{p}<0.001) .{ }^{40}$ Another of the studies found complaints of musculoskeletal pain symptoms increased across a 1-year work period. ${ }^{44}$ The knees, neck, lower back and shoulder were the common reported locations of musculoskeletal problems among rotation workers in four studies. ${ }^{1544} 7794$

Qualitative evidence similarly showed that onshore rotation workers frequently experienced physical pain and commonly reported were muscle and joint pains, neck and back pains, and leg and foot pains. ${ }^{81}$

\section{Predictors of physical health outcomes}

\section{Job demands}

Two studies reported job demands were associated with perceived poor physical health status and health complaints. ${ }^{78} 93$ One cross-sectional study reported an increase in physical workload was associated with increased level of physical strain. ${ }^{93}$ Another crosssectional study found an increase in job demand of repetitive work was associated with decreased perceived good physical health status. ${ }^{78}$

\section{Job and roster type}

Four cross-sectional studies documented job types to be associated with perceived physical health status and complaints. $^{61} 789495$ For instance, Parkes identified working in managerial $(\mathrm{RR}=1.88 ; 95 \% \mathrm{CI}=1.21$ to 2.91, $\mathrm{p}<0.01)$, construction $(\mathrm{RR}=1.84 ; 95 \% \mathrm{CI}=1.17$ to 2.89 , $\mathrm{p}<0.01)$ and drilling $(\mathrm{RR}=1.64 ; 95 \% \mathrm{CI}=1.11$ to 2.42 , $\mathrm{p}<0.05)$ roles was associated with higher risk of headache complaints compared with working in maintenance roles. ${ }^{61}$ Workers on drilling roles $(\mathrm{RR}=1.68 ; 95 \% \mathrm{CI}=1.14$ to $2.47, \mathrm{p}<0.01$ ) were also at increased risk of muscular complaints, while working in catering role $(\mathrm{RR}=0.50$; $95 \% \mathrm{CI}=0.28$ to $0.89, \mathrm{p}<0.05)$ was associated with less muscular complaints compared with working in maintenance roles. ${ }^{61}$ Another study found working in maintenance and modification role was related to perceived poor general health, while working accommodation role was related to higher symptoms of ill-health compared with other work groups. ${ }^{95}$

Two cross-sectional studies found rotation work roster type to be associated with physical health complaints. ${ }^{6194}$ One of the studies reported working a swing shift (nights-to-days shift) roster was associated with higher risk of gastric problems $(\mathrm{RR}=1.36 ; 95 \% \mathrm{CI}=1.00$ to $1.84, \mathrm{p}<0.05$ ) compared with working on day shift. ${ }^{61}$ The other study found working tour-scheduling jobs (without regular work hours) to be related to more muscular complaints. ${ }^{94}$

\section{Social support}

One cross-sectional study found an increase in social support was associated with decreased level of physical strain. ${ }^{93}$ Another cross-sectional study further identified workers with perceived high support from their supervisors were at lower risk of gastric problems $(\mathrm{RR}=0.82 ; 95 \%$ $\mathrm{CI}=0.72$ to $0.94 ; \mathrm{p}<0.01)^{61}$ and complaints of headaches $(\mathrm{RR}=0.83 ; 95 \% \mathrm{CI}=0.73$ to $0.94, \mathrm{p}<0.01) .{ }^{61}$

\section{Leadership style}

One cross-sectional study found management prioritisation of safety issues $(\mathrm{r}=-0.21 ; \mathrm{p}<0.01)$ and authentic leadership style $(r=-0.21 ; \mathrm{p}<0.01)$ to be associated with fewer subjective health complaints among workers. ${ }^{96}$

\section{Other occupational stressors}

Experiences of occupational stress were also identified to be associated with perceived physical health status and health complaints. Two cross-sectional studies identified perceived safety climate (perceived importance placed on safety in an organisation) to be associated with subjective health complaints. ${ }^{1592}$ For instance, one of the studies identified workers who were stressed by safety climate were identified to be more likely to have more muscular pains in the low back (OR=1.29; $95 \% \mathrm{CI}=1.05$ to 1.59$)$, neck $(\mathrm{OR}=1.53 ; 95 \% \mathrm{CI}=1.26$ to 1.93$)$, knees $(\mathrm{OR}=1.59$; $95 \% \mathrm{CI}=1.24$ to 2.06$)$ and shoulder (OR=1.54;95\% $\mathrm{CI}=1.20$ to 1.99$)$ compared with those who were not. ${ }^{15}$

Further two cross-sectional studies identified risk perception to be associated with physical health complaints. ${ }^{93} 96$ One study found an increase in risk perception was associated with increased physical strain. ${ }^{93}$ Likewise, the other study also reported stress from risk perception was positively related to more health complaints $(\mathrm{r}=0.24$; $\mathrm{p}<0.01) .{ }^{96}$

Similarly, one cross-sectional study reported increase in stress from communication and participation in work decisions was associated with increased physical strain. ${ }^{93}$ Additionally, another cross-sectional study found increase in occupational stress was also associated with increased complaints of ulcer-like symptoms. ${ }^{10}$

Two cross-sectional studies identified stress from physical work environment was associated with muscular pain complaints. ${ }^{1561}$ For example, one of the studies reported workers who experienced high stress from the physical work environment were more likely to complain of muscular pains in the low back $(\mathrm{OR}=1.37 ; 95 \% \mathrm{CI}=1.11$ to 1.69$)$, neck ( $\mathrm{OR}=1.43 ; 95 \% \mathrm{CI}=1.14$ to 1.79$)$ and shoulder $(\mathrm{OR}=1.32 ; 95 \% \mathrm{CI}=1.03$ to 1.68$)$ compared with those who did not. ${ }^{15}$

One cross-sectional study also found workers who experienced stress from the interface between job and family/social life were more likely to have muscular pains including in the low back $(\mathrm{OR}=1.46 ; 95 \% \mathrm{CI}=1.18$ to 1.82$)$ and shoulder $(\mathrm{OR}=1.35 ; 95 \% \mathrm{CI}=1.02$ to 1.71$)$ compared with those who did not. ${ }^{15}$ Furthermore, one cross-sectional study found increase in workers' satisfaction with employee relations and extrinsic satisfaction 
with working conditions was associated with increased level of strain. ${ }^{93}$

\section{Sleep problems and fatigue \\ Perceived sleep problem}

Studies' findings were inconsistent. Seven studies examined the levels of perceived sleep problems using selfrating $^{39561}$ and checklist. ${ }^{30} 749293$ Of these, three crosssectional studies reported prevalence ranging from $45 \%$ to $79.4 \%$ for perceived sleep problems during work periods. ${ }^{39} 5861$ Based on the sample mean scores of scales used, three studies reported scores below the threshold for subjective sleep problems (ie, low levels), ${ }^{30} 7492$ whereas one study reported moderate levels for sleep difficulties ${ }^{93}$ during work periods. Similarly, one longitudinal study also reported workers show no sleep deterioration over a 2-year period. ${ }^{30}$

Evidence from a qualitative study showed offshore workers experience poor sleep at the first and the last $2-3$ days of the leave periods. ${ }^{51}$

\section{Sleep duration}

Evidence from the studies was mixed but generally suggested short sleep duration in rotation workers during work periods. Fourteen studies examined sleep duration among rotation workers. ${ }^{31} 33476571729497-103$ Of these, two cross-sectional studies reported that $33.1 \%-$ $51.2 \%$ of workers slept for less than 6 hours during work periods. ${ }^{65} 94$ Four longitudinal studies ${ }^{33} 47101102$ further reported shorter sleep duration of less than 7 hours during work periods; with offshore rotation workers reporting an average acute sleep loss of 1.32 hours per day (95\% CI: 88.6 to $94.9 \mathrm{~min}$ ), and chronic sleep loss of 21.20 hours ( $\mathrm{SD}=08.10$ hours) per rotation or work period. ${ }^{33}$ Seven of the studies compared and found shorter sleep duration during on-shifts than on off-shifts, for both day and night shifts. ${ }^{31} 71$ 72 97-100 103 For instance, one longitudinal study found 'total sleep time' for days off $(7.0 \pm 1.9$ hours $)$ was longer than day ( $6.0 \pm 1.0$ hours $)$ and night $(6.2 \pm 1.6$ hours $)$ shifts $(p<0.001) .{ }^{97}$ Another longitudinal study reported shorter 'total sleep time' during work periods for both day $(6.1 \pm 1.0$ hours $)$ and night $(5.7 \pm 1.5$ hours $)$ shifts than days off $(7.3 \pm 1.2$ hours $) \quad(p<0.0001) .{ }^{98}$ However, in two of the studies comparing sleep among offshore rotation workers and non-rotation onshore oil workers, one crosssectional study showed longer sleep duration among offshore workers than onshore petroleum workers during day $(6.84 \pm 1.00$ hours vs $6.58 \pm 0.96$ hours $)$ and night $(6.57 \pm 1.38$ hours vs $5.62 \pm 1.33$ hours $)$ shifts $(\mathrm{p}<0.001),{ }^{103}$ while another showed long sleep duration on night shifts ( $7.20 \pm 1.3$ hours vs $5.86 \pm 1.26$ hours) but shorter on day shifts $(6.99 \pm 1.18$ hours vs $7.07 \pm 0.82$ hours $)$ than onshore petroleum workers $(\mathrm{p}<0.0001) .{ }^{100}$

\section{Sleep quality}

Studies' findings were mixed but generally suggested poor sleep quality in rotation workers during work periods. Thirteen studies examined sleep quality among rotation workers. Using cut-off points on validated scales, three studies found prevalence $(67 \%-72 \%)$ of poor sleep quality among offshore rotation workers. ${ }^{650} 804$ Ten of the studies examined sleep quality during work and leave periods. In eight of the studies, sample means based on the scales used suggested generally poorer sleep quality on both day shifts and night shifts compared with leave periods. $^{31} 3537717299100103$ For instance, one longitudinal study found sleep quality was lower (on a scale of $1-5)$ during on-shift periods $(3.3 \pm 0.8)$ compared with pre-on-shift $(3.5 \pm 0.8)$ and post-on-shift $(3.5 \pm 0.8)$ days $(\mathrm{p}<0.001) .{ }^{31}$ However, two studies showed better sleep quality during work periods. ${ }^{44}{ }^{97}$ For example, one longitudinal study found no significant differences in sleep quality during on-shifts (both day and night shifts) and off-shift days among onshore rotation workers. ${ }^{97}$ The other longitudinal study among onshore rotation workers found high sleep efficiency and good sleep quality but decreased towards the end of the work period. ${ }^{44}$ Furthermore, two cross-sectional studies compared sleep quality and found better sleep quality among offshore workers than onshore petroleum workers during day shifts ${ }^{103}$ and night shifts. ${ }^{100} 103$

\section{Sleepiness and insomnia}

Studies show sleepiness and insomnia among rotation workers. Five studies examined sleepiness and insomnia among rotation workers using cut-off points ${ }^{37} 3965$ and symptoms checklist. ${ }^{3137394465}$ Two of these studies found a $23.3 \%-27.0 \%$ prevalence of shift work disorder characterised by excessive sleepiness and insomnia, ${ }^{3965}$ and one of the studies reported $67 \%$ of offshore rotation workers had insomnia. ${ }^{65}$ Based on the mean scores of scales used, the sample means suggested high levels of sleepiness and insomnia during work periods in three studies. ${ }^{31} 374$ For example, one longitudinal study found more insomnia complaints (higher score on a scale of 0-42) at the end of work periods compared with the start of a 2-week work period $(13.8 \pm 9.6$ vs $7.1 \pm 6.8 ; \mathrm{p}<0.0005) .{ }^{37}$ Another longitudinal study reported complaints of insufficient sleep increased across a 1-year period, while severe sleepiness accumulated across the work period and was highest on the last morning shifts during work periods. ${ }^{44}$ Additionally, another longitudinal study found morning sleepiness levels were highest during work periods, while evening sleepiness also increased during offshore work periods and decreased during post-offshore work period. ${ }^{31}$

\section{Fatigue}

Findings from studies suggested high fatigue during work periods. Seven studies examined fatigue among rotation workers using cut-off points, ${ }^{34}$ self-ratings ${ }^{32} 3344$ and symptoms checklist. ${ }^{47} 7498$ Based on the mean scores of scale used, the sample means suggested high levels of fatigue during work periods in five studies ${ }^{32} 33444798$ and generally low fatigue in one study. ${ }^{74}$ Another cross-sectional study reported $73 \%$ of offshore rotation workers indicated experiencing prolonged fatigue during on-shift 
periods. ${ }^{34}$ A longitudinal study reported fatigue was lower during pre-shift than post-shift periods, but increased and accumulated faster by 0.03 points per day (on a $1-9$ scale) $(95 \% \mathrm{CI}=0.00$ to $0.07 ; \mathrm{p}=0.037)$ in postshifts compared with pre-shift periods. ${ }^{33}$ A similar longitudinal study found that daily subjective post-shift fatigue increased by 0.05 points per day (on a $1-9$ scale) $(95 \%$ $\mathrm{CI}=0.02$ to $0.08, \mathrm{p}=0.004)$ and over a 2-week offshore work period, ${ }^{32}$ though daily objective fatigue (eg, performance on a reaction time task measured by reaction times) was stable $(1.00 ; 95 \% \mathrm{CI}=0.99$ to 1.00$)$ over the course of the offshore work period. ${ }^{32}$ Another longitudinal study reported among onshore rotation workers critical levels of fatigue at the end of the day 1-3 of night shifts and after the 7 th day of a day shift. ${ }^{47}$ Furthermore, onshore rotation workers reported higher pre-sleep and post-sleep fatigue and a significantly higher post-sleep fatigue ratings during on-site days for both day and night shifts than days off in another longitudinal study. ${ }^{98}$

Similarly, two qualitative studies reported onshore and offshore rotation workers indicated fatigue as one of their main occupational health and safety issues. ${ }^{34} 105$ Another qualitative study reported fatigue among some onshore rotation workers which was indicated to affect their mood and social life at home. ${ }^{84}$

\section{Predictors of sleep and fatigue Shift/roster pattern}

Evidence showed working night shift and/or swing/ rotation shift was likely to be associated with more sleep problems than working day shifts. Four studies examined the relationship between general sleep problems and roster/shift patterns. ${ }^{5761106}$ Three of the studies found night/swing shift to be related to sleep problems. ${ }^{5761} 106$ One cross-sectional study found workers on night/swing shift were at increased risk of more sleep problems compared with day workers $(\mathrm{RR}=1.81 ; 95 \% \mathrm{CI}=1.36$ to 2.42, $\mathrm{p}<0.001) .{ }^{61}$ Additionally, one longitudinal study reported sleep efficacy was higher among offshore day shift workers than night $(93 \%$ vs $88 \%$; $\mathrm{p}<0.001)$ and swing shift workers $(93 \%$ vs $88 \%$; $\mathrm{p}<0.05) .{ }^{106}$ However, a longitudinal study reported subjective sleepiness did not differ between day, night and swing shift work periods. ${ }^{107}$

Four studies examined the relationship between sleep duration and roster/shift patterns. Three of studies found night and/or swing shifts to be related to short sleep duration ${ }^{57} 711^{106}$ For instance, one cross-sectional study found workers on a fixed-day shift reported significantly longer sleep duration than those on swing shift (nights-to-day shift; 7 nights $/ 7$ days). ${ }^{71}$ Another crosssectional study found more night/swing shift workers to have short sleep episodes than day shift workers $(44.1 \%$ vs $16.3 \%$; $\mathrm{p}<0.01) .{ }^{57}$ However, a cross-sectional study among offshore rotation workers documented longer sleep duration in swing shift workers than day shift workers. ${ }^{40}$

Eight studies examined the relationship between sleep quality and roster/shift patterns and evidence was unclear. Three of the studies reported night and/or swing shift was related to poor sleep quality. ${ }^{71} 90108$ For instance, one longitudinal study found night shift and swing shift workers reported poorer sleep quality throughout the 14 days of leave periods than in day shift workers. ${ }^{90}$ In contrast, two studies found better sleep quality working night and swing shifts. ${ }^{100} 106$ One of the studies showed better sleep quality (higher score on a scale of $0-6$ ) in night shift workers than day shift workers $(3.66 \pm 1.52$ vs $3.20 \pm 1.84 ; \mathrm{p}<0.01){ }^{100}$ The other longitudinal study reported better sleep quality (higher score on a scale of 1-5) during swing shift than during day $(3.40 \pm 0.49$ vs $3.37 \pm 0.61 ; \mathrm{p}<0.01)$ and night shifts $(3.40 \pm 0.49$ vs $3.32 \pm 0.62 ; p<0.05)$ for the first week of work period. ${ }^{106}$

Three other studies found no significant relationship between sleep quality and shift schedules. ${ }^{37} 97104$ For example, one longitudinal study reported no significant differences in the proportion of workers with better sleep quality at the start $(27.8 \%$ vs $26.9 \% ; \mathrm{p}=0.96)$ and end $(33.3 \%$ vs $44.1 \%$; $p=0.09)$ of the work period between day and swing shifts. ${ }^{37}$ Another cross-sectional study reported no differences in the proportion of workers with impaired sleep quality working fixed day $(66.1 \%)$, fixed night $(66.6 \%)$ and swing $(83.3 \%)$ shifts $(\mathrm{p}=0.34) .{ }^{104}$

Only two studies examined relationship between fatigue and shift/roster pattern. A longitudinal study found pre-sleep fatigue was higher in working night shifts compared with day shifts, but recovery of sleep on night shift was higher than day shift. ${ }^{98}$ In contrast, another longitudinal study reported no significant differences in fatigue measures such as physical and mental tiredness during night shift, and swing shift compared with day shift workers. ${ }^{90}$

Qualitative evidence study showed perceived high fatigue among onshore rotation attributed to roster patterns and sleep difficulties which improved after a change of roster from a rapid swing roster 7 nights on $/ 7$ days on $/ 7$ days off to a longer swing roster of 8 days on $/ 6$ days off $/ 8$ nights on $/ 6$ days off. ${ }^{105}$ Another qualitative study suggested high-perceived fatigue was attributed to the long shift hours of rotation work. ${ }^{34}$

\section{Job demand and control}

Two studies reported job demands and control were associated with sleep problems. ${ }^{1199}$ One cross-sectional study reported increase in workload was associated with decreased sleep duration. ${ }^{99}$ Furthermore, increase in job demands among older rotation workers was associated with decreased sleep quality than in their younger counterparts. ${ }^{99}$ Similarly, Parkes, ${ }^{11}$ in a cross-sectional study, reported increase in job demand was associated with reduced sleep duration in rotation workers who work overtime. One cross-sectional study reported increase in job control was also associated with increased sleep quality. ${ }^{99}$

Three cross-sectional studies reported working overtime was associated with short sleep duration and poor sleep quality. ${ }^{117172}$ For instance, one of the studies found offshore rotation workers working overtime of $>16$ hours 
per week during night shifts were associated with shorter sleep duration than those not working overtime. ${ }^{71}$ Another study found that an increase in working overtime was associated with decreased sleep quality among day shift workers. ${ }^{11}$

\section{Social support}

Two cross-sectional studies found social support was associated with longer sleep duration and better sleep quality. ${ }^{1199}$ One of the studies found increase in social support was related to increased sleep quality and sleep duration in day shift rotation workers. ${ }^{99}$ The other study reported increase in support from supervisors was associated with increased sleep duration in day shift workers working overtime. ${ }^{11}$

\section{Other occupational stressors}

One cross-sectional study found increase in risk perception to be associated with reduced sleep quality. ${ }^{108}$ Further, the study reported increase in perceived safety climate was associated with increased subjective sleep quality. ${ }^{108}$

Three cross-sectional studies reported adverse physical environment was associated with sleep problems. ${ }^{116199}$ For instance, one of the studies reported workers with high perception of adverse physical environment had increased risk of sleep problems $(\mathrm{RR}=1.16 ; 95 \% \mathrm{CI}=1.01$ to $1.33, \mathrm{p}<0.05) .{ }^{61}$ Two of the studies reported increase in perceived adverse physical environment was associated with decreased sleep quality among offshore rotation workers. ${ }^{11} 99$

A longitudinal study also found the increase in motion of offshore platforms was related to high incidence of physical tiredness, mental tiredness, poor sleep quality and short sleep duration. ${ }^{89}$ Similarly, qualitative evidence showed that rotation workers perceived sleep disturbances to be caused by work environmental stressors such as motion and noise of platforms, and accommodation arrangements. ${ }^{34}$

\section{Lifestyle behaviours}

Alcohol consumption

Studies showed higher alcohol consumption among rotation workers on off-shift days than in other workgroups and in the general population. Eight studies described the regular alcohol intake of rotation workers ${ }^{173435} 545580109$ : the proportion of consuming 'any' alcohol ranged from $22.1 \%$ to $84.1 \%$ across three studies ${ }^{1734109}$ and the proportion consuming alcohol above recognised safe limits ranged from $16.0 \%$ to $53.4 \%$ across four studies. ${ }^{17} 545580$ One longitudinal study found alcohol consumption was typically within the healthy consumption limit (average 1.05 standard drinks/day) among onshore workers across both on-shift and off-shift days. ${ }^{35}$

Furthermore, two longitudinal studies reported inconsistent drinking among rotation workers during on-shift days; one documented that drinking on on-shift days was at high-risk levels (median 3.0 (IQR 2.0-6.0) standard drinks per session), ${ }^{17}$ while the other reported daily drinking of average: 2 (1.7-2.8 units/day) during day shifts and 1 (median 0.6-1.4 units/day) during night shifts. ${ }^{47}$ Similarly, two other longitudinal studies compared drinking on on-shift days with off-shift days ${ }^{3547}$; and one of the studies reported drinking was less during on-shift days compared with off-shift days. ${ }^{35}$ Muller et $a l^{t 7}$ also reported rotation workers on off-shift days engage in high-risk drinking with a median of 6 (IQR 3-10) standard drinks per session and a median of 4 (IQR 2-6) standard drinks per session during on-shift.

Additionally, three cross-sectional studies compared drinking in rotation workers with non-rotation workgroups and the general population and found drinking to be consistently higher among rotation workers. ${ }^{4855} 67$ One study with comparison group compared rotation workers with onshore non-rotation workers and found more rotation workers drink alcohol at levels that have high risk of both short-term health (more than four alcoholic drinks per day) $(29.8 \% ; 95 \% \mathrm{CI}=22.8 \%$ to $36.8 \%$ vs $21.5 \%$; $95 \% \mathrm{CI}=20.2 \%$ to $22.9 \%$ ) and long-term health (more than two alcoholic drinks per day) $(64.7 \%$; $95 \%$ CI $=57.5 \%$ to $71.9 \%$ vs $50.9 \%$; $95 \%$ CI $=49.4 \%$ to $52.4 \%$ ) harm $(\mathrm{p}<0.01) .{ }^{48}$ Another study did not recruit a comparison group, only comparing the means of alcohol intake per week among offshore rotation manual workers with secondary data sources in onshore non-rotation manual industrial male workers, and reported statistically significantly higher mean units of alcohol intake per week among offshore rotation workers (49.3 units vs 21.4 units, $\mathrm{p}<0.005) .{ }^{55}$

One study recruited a general population comparison group, compared onshore rotation workers with non-rotation fathers and found higher alcohol intake scores on Alcohol Use Disorders Identification Test Scale (ie, high alcohol intake) in rotation workers than in non-rotation work fathers $(5.52 \pm 3.97$ vs $3.50 \pm 2.86$, $\mathrm{p}<0.05) .{ }^{67}$ Another study did not recruit a general population comparison group, only comparing the prevalence of drinking among offshore rotation workers with secondary data source among general male population, and reported higher prevalence of heavy drinkers among offshore rotation workers (approximately 30\% vs 10\% heavy drinkers). ${ }^{55}$

Similarly, two qualitative studies ${ }^{8410}$ described onshore work camps as having a strong 'culture of drinking', ${ }^{110}$ and another qualitative study ${ }^{49}$ noted some offshore workers indicated that the high levels of alcohol consumption among offshore workers should change.

\section{Illicit drug use}

Studies examining drug use among rotation workers were limited. Only two cross-sectional studies examined drug use and reported mixed findings: one cross-sectional study found $33.8 \%$ of onshore mining rotation worker were illicit drug users; ${ }^{43}$ however, another cross-sectional study reported $5.2 \%$ of offshore rotation workers were illicit drug users. ${ }^{80}$ 


\section{Smoking}

Studies examining smoking suggested higher smoking among rotation during on-shift days, than off-shift days and non-rotation workgroups. Fourteen studies described regular smoking in rotation workers and of these, 12 studies showed prevalence of smoking ranging from $17.7 \%$ to $47.1 \%$ across onshore and offshore rotation workers. $^{34} 374748548097103104109111112$ One crosssectional study reported a low proportion $(3.3 \%)$ of smokers among onshore rotation workers. ${ }^{58}$ Two studies examined the number of cigarettes smoked and reported rotation workers smoked on average 13.22 \pm 8.46 cigarettes per day across both on-shift and off-shift days in a daily diary study ${ }^{35}$ and mean pack of $3.04 \pm 1.9$ per day during on-shift days in a cross-sectional study. ${ }^{34}$

Two cross-sectional studies with comparison groups compared smoking among rotation workers with other non-rotation workgroups and reported smoking prevalence to be consistently higher among rotation workers than onshore non-rotation petroleum workers $(33.6 \%$ vs $20.6 \% ; \mathrm{p}<0.001)^{103}$ and other employment arrangements $(26.7 \% ; 95 \% \mathrm{CI}=20.5 \%$ to $33.0 \%$ vs $17.4 \% ; 95 \% \mathrm{CI}=16.3 \%$ to $18.5 \%, \mathrm{p}<0.01) .{ }^{48}$ One daily study examined smoking during on-shift days and off-shift days and reported rotation workers during on-shift days significantly smoke more cigarettes compared with off-shift days. ${ }^{35}$

Likewise, evidence from two qualitative studies showed smoking was common on-shift days but not a behaviour accepted by all workers, ${ }^{34}$ with some workers suggesting smoking behaviour should change. ${ }^{49}$

\section{Physical activity}

Studies reviewed suggested rotation workers engage in physical activity. Six studies examined the prevalence of physical activity among rotation workers ${ }^{17} 58809194109$ : five studies reported proportions ranging from $46.7 \%$ to $97.0 \%$ to engage in regular physical activity/exercise, ${ }^{17} 58809194$ but one other study reported a high proportion $(63.1 \%)$ of offshore rotation workers do not engage in any leisure-time exercises after work. ${ }^{109}$ Four studies examined physical activity/exercise during either on-shift days ${ }^{174794}$ and off-shift days, ${ }^{4791}$ and documented high levels of physical activity/leisure time exercises of at least 2 or more days per week. Two longitudinal studies compared physical activity on on-shift days with off-shift days. ${ }^{35} 47$ Rebar et $a l^{35}$ reported workers during on-shift days engage in fewer minutes of exercises and relaxations compared with off-shift days, but Muller et at ${ }^{47}$ reported rotation workers engaged in $>30 \mathrm{~min}$ of vigorous exercise for more days on on-shift days (median 5 days per week) against median 4 days per week during off-shift days.

One cross-sectional study with comparison groups examined physical activity/exercise among the rotation work and non-rotation workgroups, and reported the proportion of rotation workers who engaged in inadequate physical activity/exercise during leisure time or work ( $<30 \mathrm{~min}$ of physical activity) was not statistically different from that of other employment arrangements
$(40.4 \% ; 95 \% \mathrm{CI}=33.5 \%$ to $47.4 \%$ vs $46.2 \% ; 95 \% \mathrm{CI}=44.8 \%$ to $47.6 \%, \mathrm{p}>0.05) .{ }^{48}$

Qualitative evidence was mixed for onshore and offshore workers. A qualitative study reported that most onshore rotation workers engage in sporting activities more than once a week. ${ }^{110}$ However, another qualitative study discussed how some offshore rotation workers emphasised the need for a change in behaviour toward increasing physical activity. ${ }^{49}$

\section{Diet/nutrition and BMI}

Studies suggested poor nutrition or eating behaviour among rotation workers at worksites. Four studies reported perceived poor food/diet quality during work periods. $^{34355356}$ Oshaug et a $\iota^{53}$ reported high consumption of fats and carbohydrates at offshore worksites. Another cross-sectional study found a large proportion of offshore rotation workers $(45.1 \%)$ did not meet the dietary requirement of healthy eating of fruits and vegetables (five per day fruit and vegetable intake) during on-shift days. ${ }^{80}$ A cross-sectional study compared nutrition intake on-shift with the general dietary recommendations and reported offshore workers' diet may in the long term predispose them to coronary artery disease. ${ }^{53}$ One longitudinal study compared onshore workers' perception of nutrition on on-shift days with off-shift days and reported workers during on-shift days perceived their nutritional intake to be poorer compared with off-shift days ${ }^{35}$ One cross-sectional study examined the diet among the onshore rotation workers and other workgroups and reported high proportions of workers consume insufficient fruits $(48.9 \%$ vs $47.7 \%)$ and vegetables $(87.7 \%$ vs $87.9 \%$ ), but there was no difference between rotation workers and other non-rotation employment. ${ }^{48}$

Similarly, two qualitative studies ${ }^{34} 49$ also highlighted the unhealthy eating behaviours of offshore rotation workers, and workers indicated the unhealthy behaviour should change. ${ }^{49}$

Sixteen studies reported an average BMI of 26.6 43.1 $\mathrm{kg} / \mathrm{m}^{2}$ (range 22.7-28.9) $31333445-4757659497101102107111-113$ indicating rotation workers are usually overweight. Eight studies further reported a large proportion $(40.0 \%-79.3 \%)$ of rotation workers as being over-

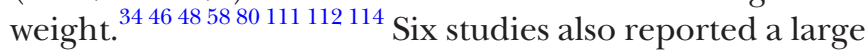
proportion $(5.5 \%-30.0 \%)$ of rotation workers as being obese. $^{344680111112114}$

Three studies compared the BMI of rotation workers with other populations. ${ }^{46} 48114$ One cross-sectional study compared onshore rotation workers with non-rotation workgroups and found a higher proportion of overweight and obesity among rotation workers than in non-rotation workgroups $(79.3 \% ; 95 \% \mathrm{CI}=73.2 \%$ to $85.5 \%$ vs $68.0 \%$; $95 \% \mathrm{CI}=66.7 \%$ to $69.4 \%, \mathrm{p}<0.01) .{ }^{48}$ No study recruited a general population comparison group, only comparing BMI with secondary data sources of the general population, found statistically significantly higher prevalence of overweightness/obesity in offshore rotation workers than the general population. ${ }^{46114}$ For instance, one of 
the studies found higher prevalence of overweightness among rotation workers aged 40-49 years compared with the same age group in the general population $(66.2 \%$ vs $50.0 \%, \mathrm{p}<0.05){ }^{46}$

\section{Predictors of lifestyle behaviours \\ Social support}

One cross-sectional study found offshore rotation workers who lack social support from supervisors were less likely to smoke $(\mathrm{OR}=0.34 ; 95 \% \mathrm{CI}=0.18$ to 0.65$)$, and those who lack support from friends were less likely to consume alcohol ( $\mathrm{OR}=0.54 ; 95 \% \mathrm{CI}=0.32$ to 0.96 ) compared with those who had support. ${ }^{109}$ Further, the study found workers who lack support from both supervisors $(\mathrm{OR}=1.74 ; 95 \% \mathrm{CI}=1.113$ to 2.65$)$ and friends $(\mathrm{OR}=1.68 ; 95 \% \mathrm{CI}=1.06$ to 2.42$)$ were more likely not to engage in leisure-time physical activities. ${ }^{109}$

Evidence from two qualitative studies ${ }^{84} 110$ suggested alcohol consumption in onshore mining rotation workers at work camps was promoted by a 'culture of drinking' that influences workers to take part in drinking if they were to fit in the social work environment. ${ }^{84}$

\section{Occupational stress}

One cross-sectional study found workers who were stressed from the interface between job and family/social life $(\mathrm{OR}=1.32 ; 95 \% \mathrm{CI}=1.02$ to 1.70$)$ and organisational structure $(\mathrm{OR}=1.35 ; 95 \% \mathrm{CI}=1.06$ to 1.74$)$ were more likely to be current consumers of alcohol compared with those who were not stressed. ${ }^{109}$ Further, the study found workers who experience high stress from safety concerns were less likely to smoke $(\mathrm{OR}=0.74 ; 95 \% \mathrm{CI}=0.58$ to 0.94 ) and more likely not to undertake leisure-time physical activities ( $\mathrm{OR}=1.44 ; 95 \% \mathrm{CI}=1.16$ to 1.79$)$ compared with those who did not. ${ }^{109}$

\section{Job type}

One cross-sectional study demonstrated job type, that is, working as a manual worker was significantly related to higher alcohol consumption than those in executive roles (49.3 vs 29.5 mean units per week; $\mathrm{p}<0.005) .{ }^{55}$

\section{Other working conditions}

Qualitative evidence also cited improvement and maintenance of exercise facilities ${ }^{49} 110$ and other work-related characteristics including time constraints due to 'long shift hours and travel times' as barriers to engaging in physical activities/exercises. ${ }^{110}$ Two other qualitative studies explored rotation workers' perception of a healthy $\operatorname{diet}^{34} 49$ and indicated workers perceived unhealthy eating of rotation workers to be connected to the availability of unhealthy food or easy access to unhealthy foods at worksites.

\section{DISCUSSION}

This review summarised studies investigating the health and well-being outcomes associated with rotation work. The findings of this review may guide and inform policy and strategies aimed at improving the health of rotation workers. Ninety studies with outcome data on mental health and well-being, physical health, sleep problems and lifestyle health-related behaviours among rotation workers in the offshore oil and gas, mining and construction sectors were included. Evidence from the studies included in the review was unclear concerning rotation workers' mental health status. However, many studies suggested poor mental health and well-being of rotation workers and particularly onshore rotation workers being more likely to experience psychological distress and suicide risk than the general population. ${ }^{52} 5960115$ This finding mirrored that of a previous review of studies with onshore rotation workers where findings, although inconsistent, pointed to a negative impact of rotation work on the mental health of onshore rotation workers. ${ }^{14}$ The differences in measurement tools including differences in measures used and the length of recall of measurement between the included studies could potentially account for the inconsistent study findings. Some studies have employed mental health outcome measures based on recall over the last 30 days, whereas others have used a recall over the last 7 days or recent experiences. These differences may reflect inconsistencies in the experiences of mental health and/or capturing of the general mental health of workers across the work phases (on-shift and off-shift) of rosters, as have been demonstrated that retrospective studies employing different recall periods are often not comparable. ${ }^{116}$ It is worth noting for future studies that studies using particularly Kessler psychological distress scale demonstrated consistent findings of high mental distress among rotation workers compared with others, and in line with previous suggestions, may well be possible to record the mental health of workers in general and across a complete roster cycle. ${ }^{14}$

Evidence from the qualitative studies highlighted rotation workers are faced with distress from, for instance, the difficulties of balancing work and home/social life $\mathrm{e}^{34518183}$ and maintaining family and social relationships, loneliness and social isolation, ${ }^{81} 8384$ and worries of overburdening partners with domestic chores. ${ }^{83} 84$ These point to difficulties for workers in adjusting and maintaining balance in life contributing to negative mental health and well-being, concurring with another review in a general population showing that working irregular shift work schedules was associated with poorer mental health. ${ }^{117}$ These findings suggest the need for interventions aimed at helping the worker to adapt and maintain balance in life which may include improved communication with families and social support. ${ }^{83}$

There was evidence to show that rotation workers perceived their general physical health as good or very good, with suggested few subjective health complaints and of better physical quality of life. Rotation workers are indicated to be self-selected population in that those who can adapt to the demands and challenges of rotation work remain in the workforce. ${ }^{6}$ Generally, rotation workers are physically healthy population, ${ }^{6}$ but there was 
limited information on mental health as most surveys relied on single items which could not capture the complexities and dimensions of mental health. However, included studies suggested offshore rotation workers have high prevalence of musculoskeletal disorders, and finding on gastric problems was unclear. The findings on gastric problems suggest the need for more studies as a previous review found evidence suggesting an association between offshore rotation work shift pattern and gastric complaints. ${ }^{6}$ Furthermore, there is available evidence that linked shift work to gastric problems as shift work disrupts the connection between eating times and diurnal stages of digestive functions such as secretion of gastric juice, ${ }^{118}$ and the job and environmental stress associated with rotation work propagate smoking, alcohol intake and less physical activity which promote gastric problems. ${ }^{10}$ Evidence on musculoskeletal disorders is in accordance with the findings reported by a previous review among offshore rotation workers. ${ }^{19}$ Musculoskeletal pain has been indicated to be a consequence of work-related activity and stress, ${ }^{1576}$ and with rotation work regarded as a stressful workplace and demanding lifestyle ${ }^{119}$ could account for the reported musculoskeletal disorders among rotation workers.

There was evidence that suggests that rotation workers during work periods or on-shift days experience sleep problems particularly short sleep duration, poor sleep quality and sleepiness. Similarly, earlier reviews have identified sleep as a concern for onshore rotation workers ${ }^{14}$ and highlighted sleep problems among offshore rotation workers. ${ }^{19}$ This is similar to other sectors such as healthcare workers with studies suggesting that long work hours (12 hours or more) has been found to negatively affect sleeping patterns. ${ }^{120}$ A systematic review has also found working shifts particularly night and early morning shifts to be associated with sleep disturbances. ${ }^{121}$ With rotation workers in the resources sector engaged in long work hours typically 12 hours per shift ${ }^{36}$ and working days compressed into day and/or night shift patterns, ${ }^{6}$ this could explain the associated sleep problems. Shift work and long shifts are indicated to unsettle the "circadian rhythm, ${ }^{\text {,22 }}$ leading to sleep disturbances. ${ }^{123}$ Furthermore, prevalence of $23.3 \%-27 \%$ of SWD was found in the current review. Working shift is indicated to be associated with the risk of SWD, and a previous review found an estimated prevalence of $10 \%-23 \%$ of SWD among rotating shift and night shift workers. ${ }^{123}$ Differences observed could be due to the differences in methods used by studies. ${ }^{6} 20$

We found rotation workers working day shifts to have better sleep outcomes particularly longer sleep duration than those working on night and swing shift patterns. This is in agreement with the findings from previous reviews among petroleum rotation workers ${ }^{6} 20$ where working night and swing shifts was associated with sleep disruptions. Night work disrupts the normal sleep-wake periods $^{124}$ and night shifts have been associated with sleep loss and other health consequences such as obesity, cancer, diabetes and coronary heart disease. ${ }^{121}$ McKenna and Wilkes have documented unimpeded morning sleep 'before the first shift' coupled with afternoon naps could reduce sleep debt prior to starting a roster of night shifts. ${ }^{124}$ Organisations could encourage workers to take uninterrupted sleeps the day before commuting to worksites ${ }^{124}$; and look at instituting long changeovers of possibly more than 24 hours change window particularly for workers on swing shifts who may change from day shifts to night shifts to allow for enough sleep. ${ }^{97}$ Furthermore, organisation could create the enabling environment such as reducing noise and light, and competing social activities ${ }^{98}$ at camp sites to promote sleep after a night shift to enable the necessary recovery of sleep.

The evidence reviewed showed a high level of fatigue among rotation workers, which increases and accumulates over the course of work periods. Findings from a previous review have also highlighted increased fatigue among offshore rotation workers. ${ }^{6}$ Fatigue among rotation workers has been indicated to be due to the long work hours ${ }^{634}$ roster length ${ }^{47}$ and sleep disturbances. ${ }^{84105}$ Working long hours (>12 hours) ${ }^{125}$ and shifts ${ }^{126}$ have also been found to be associated with high fatigue among other work populations. A high level of fatigue is detrimental to performance and safety ${ }^{47}$ particularly in critical safety risk resource industry. Strategies aimed at training workers could include ways to identifying and mitigating against fatigue, and allowing for breaks and enough periods between shifts for rest and recovery ${ }^{97}$ among others as 'successive days-on-shift and chronic sleep loss' increase the risk of fatigue. ${ }^{33}$

Studies reviewed showed a high intake of alcohol in rotation workers during off-shift days. Studies provided information on the pattern of drinking of rotation workers as high above safe limits, ${ }^{17345580}$ and very high on off-shift days, ${ }^{173547}$ and higher than other workgroups ${ }^{48}$ and general male population. ${ }^{5567}$ These findings are in accordance with the findings of previous reviews in onshore rotation workers ${ }^{14}$ and offshore rotation workers ${ }^{19}$ which reported high alcohol consumption. Men typically drink more alcohol than women; with per capita consumption of ' 19.4 litres' compared with '7.0 litres' of undiluted alcohol among women drinkers, ${ }^{127}$ and with rotation workers being predominately men $^{614119}$ could explain the high level of alcohol intake among this working group. Furthermore, the social environment of rotation worksite particularly onshore sites (eg, in Australia) has been reported as supportive toward alcohol drinking as workers take up drinking to socially fit at the worksite. ${ }^{84}{ }^{110}$ Alcohol consumption particularly among offshore workers during off-shift days has also been indicated to be an expression of freedom from the worksite. ${ }^{128}$ Given that risky alcohol consumption is a major cause of disability and poor health and contributes to several deaths, ${ }^{129}$ and as suggested by Rebar et $a l,{ }^{35}$ interventions should target both on-site and off-site drinking among rotation workers taking into account personal, social and environmental factors that promote 
the intake of alcohol at risky levels. This may include the restriction of the availability of alcohol at onshore worksites and increasing awareness of the negative health consequences of risky alcohol intake. ${ }^{129}$

Evidence on illicit drug use was limited with findings not showing any clear direction of use among rotation workers; therefore, further research examining the use of illicit drug among rotation workers is required.

Reported levels of smoking among rotation workers were high ${ }^{48} 80109$ and suggested to be higher than other workgroups ${ }^{48} 103$ and during on-shift days than off-shift days. ${ }^{35}$ Similarly, a narrative review has also highlighted a high prevalence of smoking among offshore rotation workers. ${ }^{19}$ It has been documented that smoking and desires to smoke are associated with experiencing high levels of stress ${ }^{130}$ as such the stressful work conditions associated with rotation work arrangement ${ }^{19119}$ could be driving rotation workers to smoke. Smoking is recognised as a major cause of several health conditions and premature death, and with no safe limits. ${ }^{131}$ Therefore, evidence from the review suggests the need to provide health interventions that are aimed at the cessation of smoking such as group behaviour therapy and individual counselling ${ }^{132}$ which could include stress management for rotation workers. ${ }^{35}$

The main findings from included studies regarding physical activity suggested a large proportion of workers engage in regular leisure-time physical activity/exercise, ${ }^{1758} 809194$ during either on-shift days ${ }^{174794}$ and offshift days. ${ }^{4791}$ A previous review also reported offshore rotation workers engaging in physical activity mostly on off-shift days. ${ }^{19}$ Rotation worksites usually provide recreational facilities ${ }^{6} 110$ which may have encouraged rotation workers to engage in physical activity/exercise and help maintain fitness. ${ }^{84}$ Nonetheless, engaging in physical activities/exercises on-site has been indicated to be restricted by long working hours and fatigue/tiredness from work. ${ }^{110}$ Long working hours is one of the many negative aspects of rotation work arrangements.

The studies reviewed on nutrition/diet reported findings that suggest poor nutrition among rotation workers at worksites. This is in line with findings of a previous review where offshore rotation workers perceived their diet as unhealthy. ${ }^{19}$ Easy access or availability of unhealthy food at worksites has been noted to promote the unhealthy eating behaviour of workers. ${ }^{34} 49$ Unavailability of healthy food has been identified as a barrier to healthy eating in workers ${ }^{133}$ and one study has demonstrated that providing shift workers with healthy foods effectively improved their dietary intake during working days. ${ }^{134}$ Only one study ${ }^{35}$ examined nutrition during offsite in relation to on-site days as such not much is known about rotation workers' nutrition during leave periods. Furthermore, studies found higher levels of overweight and obesity among rotation workers compared with the general population. A similar finding was reported in a previous review among offshore rotation workers. ${ }^{19}$ The intake of unhealthy foods has been indicated to be linked to obesity. ${ }^{135}$ The unhealthy eating behaviour among rotation workers is likely to explain the findings on overweight and obesity. Evidence therefore suggests the need to provide healthy food options at rotation worksites which could improve the dietary intake of rotation workers. ${ }^{134}$

\section{Work-related factors associated with health outcomes of rotation workers}

The evidence reviewed suggested a wide range of workrelated factors determining mental health outcomes in rotation workers. These included job demands (job task, workload and emotional demands), roster and shift length, occupational stressors, work-home interference, leadership style, job control/autonomy, role clarity, workplace bullying and social support.

Evidence on factors determining physical health, sleep problems and lifestyle behaviours was scarce to make firm conclusions, but potentially suggests perceived physical health and complaints to be associated with job type, job demands and occupational stressors; shift pattern (swing shift), social support and occupational stressors to be associated with gastric problems while job type, shift pattern and occupational stressors (physical environment/workplace) to be associated with musculoskeletal disorders. Furthermore, sleep problems were associated with shift/roster patterns (night/swing shifts), job demands and control (workload, working overtime, long shift hours), environmental stressors (safety climate, risk perception, adverse physical environment) and social support; and lifestyle behaviours were associated with social support, occupation stress from work-home interference and safety climate, job type, long work hours, availability of unhealthy food and management of recreational facilities.

The findings from the review align with the Job Demands-Resources (JD-R) Model. ${ }^{119} 136$ The JD-R Model stipulates two different categories of intrinsic occupational risk factors: job demands and resources which through 'two underlying psychological processes play a role in the development of job strain and motivation' (p313) to influence the well-being of workers. ${ }^{136}$ These risk factors are the physical, psychological, social or organisational components of a job. Job demands such as job task, workload, emotional demands, high work pressure, harsh physical environment, etc necessitate sustained mental, emotional or physical effort or skills to deal with, and contribute to job strain. ${ }^{136}$ Job resources such as job control/autonomy, role clarity, job security, and social support help in attaining work goals and/or that reduces job demands, and the associated negative (physiological and psychological) effects arouse personal learning and development, and contribute to motivation. ${ }^{119}{ }^{136}$ Vojnovic et al ${ }^{19}$ have discussed similar workrelated factors and have stated rotation work is inherent in several job demands and as such available job resources are particularly significant and should be maximised to mitigate employee strain and subsequent health. More 
research is needed to further examine the work-related factors associated with the health indicators particularly the physical health outcomes, sleep problems and lifestyle behaviours of rotation workers.

\section{Strengths and limitations}

This systematic review has several strengths; it provided a comprehensive overview of factors associated with health and well-being of rotation workers in resource industry, assessing the literature across different work sectors, countries and all relevant health indicators (covering factors associated with mental and physical health). The inclusion of quantitative and qualitative findings was also a strength as qualitative findings support quantitative evidence by giving in-depth insights into the health outcomes of rotation work, and mixed evidence synthesis has indicated to enrich the effectiveness of findings and decision-making.

This review is not without limitations that should be acknowledged. The review included only published research and as such, the results of the study might be subject to publication bias. Only studies published in English were included which may have limited the scope, but there is evidence that suggests no systematic bias in reviews where only studies written in English are included. ${ }^{137}$ The review only reviewed significant work-related factors determining health outcomes and health-related behaviours. However, there is evidence of sociodemographic characteristics that are associated with health outcomes and also moderate the associations between work-related factors determining health outcomes, ${ }^{119}$ which could be explored by future reviews.

\section{Limitations of the assessed literature}

There are few longitudinal studies on health outcome measures, however, the available cross-sectional studies assessed extensively mental health outcomes with a few investigating physical health and health-related behaviour outcomes. Furthermore, most of the studies have used cross-sectional designs and as such making causal interpretations of the findings from these studies is limited. Studies included had a greatly varied number of participants; quantitative studies included participants ranging from $n=19^{36}$ to $n=9945,{ }^{95}$ with several studies including small sample sizes ${ }^{5866567}$ which affect their conclusions. The qualitative studies included study participants ranging from $n=7^{110}$ to $n=68,{ }^{34}$ and while the sample is suitable for the kind of method used, it does not reflect the entirety of rotation work population. ${ }^{14} \mathrm{~A}$ vast majority of the studies selected study participants using non-probability convenience sampling technique which has been indicated to be a suitable way to draw responses from a mobile population such as rotation workers. ${ }^{58}$ This may, however, result in the non-representativeness of the recruited sample. It is also possible that certain characteristics of participants may influence their participation, thus those most negatively impacted by rotation work may be more likely to take part in the survey or equally may be more likely not to take part in the study. ${ }^{14}$ Some of the studies, particularly those that examined health-related behaviours, also used non-validated measures which affect the rigour in methods. ${ }^{14}$ Again, the findings of some of the studies were descriptive, for example ${ }^{559495}$ and as such interpretations and drawing of general conclusions from the findings of these studies should be done with caution.

\section{Implications for policy and future research}

Addressing health challenges faced by rotation workers should be a key task for policymakers and resource industry management. In this regard, organisations should support interventions that identify, prioritise and mitigate against mental and physical health problems and promote behavioural changes. Such interventions should also create workplace environments that minimise the negative aspects of rotation workstyle and maximise the positive aspects to support rotation workers to reduce job stress and promote health.

There is clear evidence that considerable efforts are being made in understanding the well-being of rotation workers. However, there is still inconsistency in the findings particularly on mental health outcomes such as psychological distress (depression, anxiety and stress) and well-being that require further research to clarify. There are limited rigorous studies that explore physical health problems and healthrelated behaviours and as such, there is the need for further studies to examine the work-related factors associated with the physical health problems and lifestyle behaviours of rotation workers. There are also limited interventional studies; interventional studies are therefore needed to improve health in this population and the cross-sectional research gives nice foundations for understanding factors that should be addressed in these interventions. Generally, there are limited longitudinal studies that explore the long-term health effects of rotation work and the short-term variations of health outcomes of rotation workers to give insight into how rotation workers' experience of health issues and their significant predictors change over time and across context.

\section{CONCLUSION}

Evidence from both qualitative and quantitative studies has suggested psychological distress and suicide risk among onshore rotation workers at higher levels than the general population; and more sleep problems (short sleep duration, poor sleep quality and sleepiness) and fatigue, smoking and poor nutrition during work periods among rotation workers in the offshore oil and gas, mining and construction industries. Evidence has also suggested rotation workers consume higher levels of alcohol during off-shift days and are more overweight and obese than the general population. Rotation workers reported perceived good physical health and engaged in leisure-time physical activity. Job demands of rotation work arrangements were associated with poor physical and mental health outcomes, while the job resources available were associated with better physical and mental 
health outcomes. Hence, interventions could target minimising job demands and maximising the available job resources to support rotation workers to adapt and maintain balance in life, and to reduce job stress to promote health.

\section{Author affiliations}

${ }^{1}$ School of Population Health, Faculty of Health Sciences, Curtin University, Perth, Western Australia, Australia

${ }^{2}$ Health Psychology, Institute of Applied Health Sciences, University of Aberdeen, Aberdeen, UK

${ }^{3}$ Faculty of Psychology, SWPS University of Social Sciences and Humanities, Wroclaw, Poland

${ }^{4}$ NHMRC CRE in Digital Technology to Transform Chronic Disease Outcomes,

Melbourne School of Population and Global Health, University of Melbourne,

Melbourne, Victoria, Australia

${ }^{5}$ Rowett Institute, University of Aberdeen, Aberdeen, UK

Twitter Bernard Yeboah-Asiamah Asare @kojo_asiamah, Dominika Kwasnicka @dkwasnicka, Daniel Powell @DanPowell83 and Suzanne Robinson @RobinsonSuz

Acknowledgements The authors extend their sincere gratitude to Ms Diana Blackwood and Ms Vanessa Varis, Librarian for Faculty of Health Sciences, at Curtin University for their professional assistance in developing the review search strategy.

Contributors BY-AA, DK, DP and SR conceived and designed the study protocol. BY-AA drafted the initial manuscript. DK, DP and SR reviewed and contributed to the initial question development, search strategy, study selection criteria, study reviewing, summary and assessment. BY-AA drafted the article and DK, DP and SR have reviewed and approved the final written manuscript.

Funding The study was funded by Aberdeen-Curtin Alliance Curtin International Postgraduate Research Scholarship (CIPRS). BY-AA is a recipient of AberdeenCurtin Alliance PhD CIPRS and Research Stipend Scholarship.

\section{Competing interests None declared.}

Patient consent for publication Not required.

Ethics approval This study summarised data from previously published studies, as such did not require ethics approval.

Provenance and peer review Not commissioned; externally peer reviewed.

Data availability statement All data relevant to the study are included in the article or uploaded as supplemental information.

Supplemental material This content has been supplied by the author(s). It has not been vetted by BMJ Publishing Group Limited (BMJ) and may not have been peer-reviewed. Any opinions or recommendations discussed are solely those of the author(s) and are not endorsed by BMJ. BMJ disclaims all liability and responsibility arising from any reliance placed on the content. Where the content includes any translated material, BMJ does not warrant the accuracy and reliability of the translations (including but not limited to local regulations, clinical guidelines, terminology, drug names and drug dosages), and is not responsible for any error and/or omissions arising from translation and adaptation or otherwise

Open access This is an open access article distributed in accordance with the Creative Commons Attribution Non Commercial (CC BY-NC 4.0) license, which permits others to distribute, remix, adapt, build upon this work non-commercially, and license their derivative works on different terms, provided the original work is properly cited, appropriate credit is given, any changes made indicated, and the use is non-commercial. See: http://creativecommons.org/licenses/by-nc/4.0/.

\section{ORCID iDs}

Bernard Yeboah-Asiamah Asare http://orcid.org/0000-0002-1381-4981

Dominika Kwasnicka http://orcid.org/0000-0002-5961-837X

Daniel Powell http://orcid.org/0000-0003-4995-6057

Suzanne Robinson http://orcid.org/0000-0001-5703-6475

\section{REFERENCES}

1 Storey K. Fly-in/Fly-out and Fly-over: mining and regional development in Western Australia. Aust Geogr 2001;32:133-48.
2 Vodden $\mathrm{K}$, Hall $\mathrm{H}$. Long distance commuting in the mining and oil and gas sectors: implications for rural regions. Extr Ind Soc 2016;3:577-83.

3 Storey K. The evolution of commute work in the resource sectors in Canada and Australia. Extr Ind Soc 2016;3:584-93.

4 Langdon RR, Biggs HC, Rowland B. Australian fly-in, fly-out operations: impacts on communities, safety, workers and their families. Work 2016;55:413-27.

5 Haslam McKenzie FM, Hoath A. The socio-economic impact of mine industry commuting labour force on source communities. Resour Policy 2014;42:45-52.

6 Parkes KR. Shift schedules on North sea oil/gas installations: a systematic review of their impact on performance, safety and health. Saf Sci 2012;50:1636-51.

7 Storey K. Fly-in/Fly-out: implications for community sustainability. Sustainability 2010;2:1161-81.

8 Mckenzie FH. Fly-in fly-out : the challenges of transient populations in rural landscapes. In: Luck G, Black R, Race D, eds. Demographic Change in Australia's Rural Landscapes. Landscape Series. Springer, Dordrecht, 2010: 325-74.

9 Parkes KR. Working hours in the offshore petroleum industry, Current knowledge and research needs regarding extended work periods and shift work offshore. In: Work time arrangements in the petroleum industry Stavanger, Norway: petroleum safety authority, 2007: 1-27.

10 Chen W-Q, Wong T-W, Yu T-S. Direct and interactive effects of occupational stress and coping on ulcer-like symptoms among Chinese male off-shore oil workers. Am J Ind Med 2009;52:500-8.

11 Parkes KR. Work environment, overtime and sleep among offshore personnel. Accid Anal Prev 2017;99:383-8.

12 Meredith V, Rush P, Robinson E. Fly-in Fly-out workforce practices in Australia: the effects on children and family relationships. Melbourne: Australian Institute of Family Studies, 2014.

13 Barclay MA, Harris J, Everingham JA. Factors Linked to the WellBeing of Fly-in, Fly-out' Workers. Brisbane, QLD: University of Queensland, 2014.

14 Parker S, Fruhen L, Burton C. Impact of FIFO work arrangements on the mental health and wellbeing of FIFO workers. Australia: Centre for Transformative Work Design, 2018.

15 Chen WQ, Yu IT-S, Wong TW. Impact of occupational stress and other psychosocial factors on musculoskeletal pain among Chinese offshore oil installation workers. Occup Environ Med 2005;62:251-6.

16 Ljoså $\mathrm{CH}$, Tyssen R, Lau B. Mental distress among shift workers in Norwegian offshore petroleum industry--relative influence of individual and psychosocial work factors. Scand J Work Environ Health 2011;37:551-5.

17 Carter A, Muller R. Hydration knowledge, behaviours and status of staff at the residential cAMP of a fly-in/fly-out minerals extraction and processing operation in tropical north-eastern Australia. Ind Health 2007;45:579-89.

18 Vojnovic P, Bahn S. Depression, anxiety and stress symptoms among Fly-In Fly-Out Australian resource industry workers. J Heal Saf Env 2015;31:207-23.

19 Gibson Smith KL, Paudyal V, Stewart DJ. The health and wellbeing of offshore workers : a narrative review of the published literature. $J$ Inst Remote Healthc 2015;6:10-23.

20 Fossum IN, Bjorvatn B, Waage S, et al. Effects of shift and night work in the offshore petroleum industry: a systematic review. Ind Health 2013:51:530-44.

21 Parkes KR. Psychosocial aspects of stress, health and safety on North sea installations. Scand J Work Environ Health 1998;24:321-33.

22 Lizarondo L, Stern C, Carrier J. Mixed Methods Systematic Reviews. In: Aromataris E, Munn Z, eds. Jonna Briggs Institute, 2020.

23 Moher D, Liberati A, Tetzlaff J, et al. Preferred reporting items for systematic reviews and meta-analyses: the PRISMA statement. Ann Intern Med 2009;151:264-9.

24 Babineau J. Product review: Covidence (systematic review software). J Can Health Libr Assoc 2014;35:68.

25 Moola S, Munn Z, Tufanaru C. Systematic reviews of etiology and risk. In: Aromataris E, Munn Z, eds. Joanna Briggs Institute Reviewer's Manual. The Joanna Briggs Institute, 2017: 6.

26 Turgoose D, Maddox L. Predictors of compassion fatigue in mental health professionals: a narrative review. Traumatology 2017;23:172-85.

27 Duran B. Posttraumatic growth as experienced by childhood cancer survivors and their families: a narrative synthesis of qualitative and quantitative research. J Pediatr Oncol Nurs 2013:30:179-97. 
28 Lucas PJ, Baird J, Arai L, et al. Worked examples of alternative methods for the synthesis of qualitative and quantitative research in systematic reviews. BMC Med Res Methodol 2007;7:1-7.

29 Albrecht SL, Anglim J. Employee engagement and emotional exhaustion of fly-in-fly-out workers: a diary study. Aust J Psychol 2018;70:66-75.

30 Hanoa R, Baste V, Kooij A, et al. No difference in self reported health among coalminers in two different shift schedules at Spitsbergen, Norway, a two years follow-up. Ind Health 2011;49:652-7.

31 Riethmeister V, Bültmann U, De Boer MR, et al. Examining courses of sleep quality and sleepiness in full 2 weeks on/2 weeks off offshore day shift rotations. Chronobiol Int 2018;35:759-72.

32 Riethmeister V, Bültmann U, Gordijn M, et al. Investigating daily fatigue scores during two-week offshore day shifts. Appl Ergon 2018;71:87-94.

33 Riethmeister V, Matthews RW, Dawson D, et al. Time-of-day and days-on-shift predict increased fatigue over two-week offshore day-shifts. Appl Ergon 2019;78:157-63.

34 Riethmeister V, Brouwer S, van der Klink J, et al. Work, eat and sleep: towards a healthy ageing at work program offshore. BMC Public Health 2016;16:134.

35 Rebar AL, Alfrey K-L, Gardner B, et al. Health behaviours of Australian fly-in, fly-out workers and partners during on-shift and off-shift days: an ecological momentary assessment study. BMJ Open 2018;8:1-7.

36 Harris A, Waage S, Ursin $\mathrm{H}$, et al. Cortisol, reaction time test and health among offshore shift workers. Psychoneuroendocrinology 2010;35:1339-47.

37 Waage S, Pallesen S, Moen BE, et al. Sleep and health in oil rig workers--before and after a two week work period offshore. Ind Health 2013;51:172-9.

38 Sutherland VJ, Cooper CL, Personality CCL. Personality, stress and accident involvement in the offshore oil and gas industry. Pers Individ Dif 1991;12:195-204.

39 Waage S, Moen BE, Pallesen S, et al. Shift work disorder among oil rig workers in the North sea. Sleep 2009;32:558-65.

40 Waage S, Pallesen S, Moen BE, et al. Shift work and age in the offshore petroleum industry. Public Health 2010;16:251-7.

41 Miller P, Brook L, Stomski N, et al. Bullying in Fly-In-Fly-Out employees in the Australian resources sector: a cross-sectional study. PLoS One 2020;15:e0229970.

42 Miller P, Brook L, Stomski NJ, et al. Depression, suicide risk, and workplace bullying: a comparative study of fly-in, fly-out and residential resource workers in Australia. Aust Health Rev 2020;44:248-8.

43 James C, Tynan R, Roach D, et al. Correlates of psychological distress among workers in the mining industry in remote Australia: evidence from a multi-site cross-sectional survey. PLoS One 2018;13:e0209377.

44 Kecklund G, Ekstedt M, Akerstedt T. The effects of doubleshifts (15.5 hours) on sleep, fatigue and health. J Hum Ergol 2001;30:53-8.

45 Light IM, Gibson MG. Application of weight-height relations for assessing adiposity in a United Kingdom offshore workforce. $\mathrm{Br} J$ Ind Med 1987;44:201-5.

46 Light IM, Gibson M. Percentage body fat and prevalence of obesity in a UK offshore population. Br J Nutr 1986;56:97-104.

47 Muller R, Carter A, Williamson A. Epidemiological diagnosis of occupational fatigue in a fly-in fly-out operation of the mineral industry. Ann Occup Hyg 2008;52:63-72.

48 Joyce SJ, Tomlin SM, Somerford PJ, et al. Health behaviours and outcomes associated with fly-in fly-out and shift workers in Western Australia. Intern Med J 2013;43:440-4.

49 Gibson Smith K, Paudyal V, Quinn F, et al. Offshore workers and health behaviour change: an exploration using the theoretical domains framework. Int Marit Health 2018;69:248-56.

50 Gann M, Corpe UNA, Wilson I. The application of a short anxiety and depression questionnaire to oil industry staff. Occup Med 1990;40:138-42

51 Rodrigues VF, Fischer FM, Brito MJ. Shift work at a modern offshore drilling rig. J Hum Ergol 2001;30:167-72.

52 Sellenger M, Oosthuizen J. Quantitative analysis of mental wellbeing of fly-in fly-out construction project support service workers. J Prev Med Heal 2017;1:1001.

53 Oshaug A, Ostgård LI, Trygg KU. Diet among oil-workers on offshore oil installations in the Norwegian sector of the North sea. $\mathrm{Br} J$ Nutr 1992;68:11-19.

54 Sutherland VJ. The use of a stress audit. Leadersh Organ Dev J 1993;14:22-8.
55 Aiken GJ, McCance C. Alcohol consumption in offshore oil rig workers. Br J Addict 1982;77:305-10.

56 Maniscalco P, Lane R, Welke M, et al. Decreased rate of back injuries through a wellness program for offshore petroleum employees. J Occup Environ Med 1999;41:813-20.

57 Menezes MCR, Pires MLN, Benedito-Silva AA, et al. Sleep parameters among offshore workers: an initial assessment in the Campos Basin, Rio de Janeiro, Brazil. Chronobiol Int 2004;21:889-97.

58 Barclay MA, Harris J, Everingham J-A, et al. Geologists, FIFO work practices and job satisfaction. Applied Earth Science 2016;125:221-30.

59 Bowers J, Lo J, Miller P, et al. Psychological distress in remote mining and construction workers in Australia. Med J Aust 2018;208:391-7.

60 Lester L, Waters S, Spears B, et al. Parenting adolescents: developing strategies for FIFO parents. J Child Fam Stud 2015;24:3757-66.

61 Parkes KR, Shiftwork PKR. Shiftwork, job type, and the work environment as joint predictors of health-related outcomes. $J$ Occup Health Psychol 1999;4:256-68.

62 Nielsen MB, Tvedt SD, Matthiesen SB. Prevalence and occupational predictors of psychological distress in the offshore petroleum industry: a prospective study. Int Arch Occup Environ Health 2013:86:875-85.

63 Pavicic Žeželj S, Cvijanovic Peloza O, Mika F, et al. Anxiety and depression symptoms among gas and oil industry workers. Occup Med 2019;69:22-7.

64 Berthelsen M, Pallesen S, Bjorvatn B, et al. Shift schedules, work factors, and mental health among onshore and offshore workers in the Norwegian petroleum industry. Ind Health 2015;53:280-92.

65 Sadeghniiat-Haghighi K, Zahabi A, Najafi A, et al. Evaluating the quality and duration of sleep using actigraphy in petroleum industry shift workers. Sleep Health 2020;6:407-10.

66 Cooke DC, Kendall G, Li J, et al. Association between pregnant women's experience of stress and partners' fly-in-fly-out work. Women Birth 2019;32:e450-8.

67 Dittman CK, Henriquez A, Roxburgh N. When a non-resident worker is a non-resident parent: investigating the family impact of Fly-In, Fly-Out work practices in Australia. J Child Fam Stud 2016;25:2778-96.

68 Slade T, Johnston A, Teesson M. The mental health of Australians 2: report on the 2007 national survey of mental health and wellbeing. Canberra, Australia: Department of Health and Ageing, 2009.

69 Parkes KR. Mental health in the oil industry: a comparative study of onshore and offshore employees. Psychol Med 1992;22:997-1009.

70 Cooper CL, Sutherland VJ, stress J. Job stress, mental health, and accidents among offshore workers in the oil and gas extraction industries. J Occup Med 1987;29:119-25.

71 Parkes KR. Shift rotation, overtime, age, and anxiety as predictors of offshore sleep patterns. J Occup Health Psychol 2015;20:27-39.

72 Parkes KR. Sleep patterns of offshore day-workers in relation to overtime work and age. Appl Ergon 2015;48:232-9.

73 Birkeland Nielsen M, Glasø L, Berge Matthiesen S, et al. Bullying and risk-perception as health hazards on oil rigs. J Manag Psychol 2013;28:367-83.

74 Sneddon A, Mearns K, Flin R. Stress, fatigue, situation awareness and safety in offshore drilling crews. Saf Sci 2013;56:80-8.

75 Mathisen GE, Bergh LIV. Action errors and rule violations at offshore oil rigs: the role of engagement, emotional exhaustion and health complaints. Saf Sci 2016;85:130-8.

76 Bergh LIV, Leka S, Zwetsloot GIJM. Tailoring psychosocial risk assessment in the oil and gas industry by exploring specific and common psychosocial risks. Saf Health Work 2018;9:63-70.

77 Bergh LIV, Hinna S, Leka S, et al. Developing and testing an interna audit tool of the psychosocial work environment in the oil and gas industry. Saf Sci 2016;88:232-41.

78 Bjerkan AM. Work and health: a comparison between Norwegian onshore and offshore employees. Work 2011;40:125-42.

79 Chen WQ, Wong TW, Yu TS. Mental health issues in Chinese offshore oil workers. Occup Med 2009;59:545-9.

80 Gibson Smith K, Paudyal V, Klein S, et al. Health, self-care and the offshore workforce - opportunities for behaviour change interventions, an epidemiological survey. Rural Remote Health 2018;18:4319.

81 Wright AC, Griep Y. Burning the midnight oil: Examining wellbeing and vulnerability in Alberta's oil patch. Extr Ind Soc 2019;6:77-84.

82 Ebert A, Strehlow K. Does on-site chaplaincy enhance the health and well being of fly-in, fly-out (FIFO) personnel? Health Promot $J$ Austr 2017;28:118-22. 
83 Gardner B, Alfrey K-L, Vandelanotte C, et al. Mental health and well-being concerns of fly-in fly-out workers and their partners in Australia: a qualitative study. BMJ Open 2018;8:e019516.

84 Torkington AM, Larkins S, Gupta TS. The psychosocial impacts of fly-in fly-out and drive-in drive-out mining on mining employees: a qualitative study. Aust J Rural Health 2011;19:135-41.

85 Carter T, Kaczmarek EA. An Exploration of Generation Y's experience of offshore Fly-in/Fly-out employment. Aust Community Psychol 2009;21:52-66.

86 Pirotta J. An exploration of the experiences of women who FIFO. Aust Community Psychol 2009;21:37-51.

87 Chen W-Q, Wong T-W, Yu T-S. Influence of occupational stress on mental health among Chinese off-shore oil workers. Scand J Public Health 2009;37:766-73.

88 Chen W-qing, Wong T-wai, Yu T-sun. Determinants of perceived occupational stress among Chinese offshore oil workers. Work Stress 2003;17:287-305.

89 Haward BM, Lewis $\mathrm{CH}$, Griffin MJ. Motions and crew responses on an offshore oil production and storage vessel. Appl Ergon 2009;40:904-14

90 Merkus SL, Holte KA, Huysmans MA, et al. Self-Reported recovery from 2-week 12-hour shift work schedules: a 14-day follow-up. Saf Health Work 2015;6:240-8.

91 Merkus SL, Huysmans MA, Holte KA, et al. An active transition from offshore work to family life: activities that may impact recovery. Work 2017;58:371-81.

92 Nielsen MB, Hystad SW, Eid J. The brief Norwegian safety climate inventory (brief NORSCl) - psychometric properties and relationships with shift work, sleep, and health. Saf $\mathrm{Sci}$ 2016;83:23-30.

93 Ulleberg P, Rundmo T, et al. Job stress, social support, job satisfaction and absenteeism among offshore oil personnel. Work Stress 1997;11:215-28.

94 Kalteh $\mathrm{HO}$, Khoshakhlagh $\mathrm{AH}$, Rahmani N. Prevalence of musculoskeletal pains and effect of work-related factors among employees on offshore oil and gas installations in Iran. Work 2018;61:347-55.

95 Bjerkan AM. Health, environment, safety culture and climate analysing the relationships to occupational accidents. J Risk Res 2010;13:445-77.

96 Nielsen MB, Eid J, Hystad SW, et al. A brief safety climate inventory for petro-maritime organizations. Saf Sci 2013;58:81-8.

97 Paech GM, Jay SM, Lamond N, et al. The effects of different roster schedules on sleep in miners. Appl Ergon 2010;41:600-6.

98 Ferguson SA, Baker AA, Lamond N, et al. Sleep in a live-in mining operation: the influence of start times and restricted non-work activities. Appl Ergon 2010;42:71-5.

99 Parkes KR. Age and work environment characteristics in relation to sleep: additive, interactive and curvilinear effects. Appl Ergon 2016;54:41-50.

100 Parkes KR. Sleep patterns, shiftwork, and individual differences: a comparison of onshore and offshore control-room operators. Ergonomics 1994;37:827-44.

101 Thorne HC, Hampton SM, Morgan LM, et al. Returning from night shift to day life: beneficial effects of light on sleep. Sleep Biol Rhythms 2010;8:212-21.

102 Thorne H, Hampton S, Morgan L, et al. Differences in sleep, light, and circadian phase in offshore 18:00-06:00 $\mathrm{H}$ and 19:00-07:00 H shift workers. Chronobiol Int 2008;25:225-35.

103 Parkes KR. Age, smoking, and negative affectivity as predictors of sleep patterns among shiftworkers in two environments. J Occup Health Psychol 2002;7:156-73.

104 Sadeghniiat-haghighi K, Aminian O, Najafi A. Sleep quality in shift workers of offshore petroleum industries 2018;3:36-40.

105 Devine SG, Muller R, Carter A. Using the framework for health promotion action to address staff perceptions of occupational health and safety at a fly-in/fly-out mine in north-west Queensland. Health Promot J Aust 2008;19:196-202.

106 Saksvik IB, Bjorvatn B, Harvey AG, et al. Adaptation and readaptation to different shift work schedules measured with sleep diary and actigraphy. J Occup Health Psychol 2011;16:331-44.

107 Waage S, Harris A, Pallesen S, et al. Subjective and objective sleepiness among oil rig workers during three different shift schedules. Sleep Med 2012;13:64-72.

108 Hope S, Øverland S, Brun W, et al. Associations between sleep, risk and safety climate: a study of offshore personnel on the Norwegian continental shelf. Saf Sci 2010;48:469-77.

109 Chen W-Q, Wong TW, Yu IT-S. Association of occupational stress and social support with health-related behaviors among Chinese offshore oil workers. J Occup Health 2008;50:262-9.
110 Perring A, Pham K, Snow S, et al. Investigation into the effect of infrastructure on fly-in fly-out mining workers. Aust J Rural Health 2014;22:323-7.

111 Parkes KR. Shift work and age as interactive predictors of body mass index among offshore workers. Scand J Work Environ Health 2002;28:64-71.

112 Parkes KR. Demographic and lifestyle predictors of body mass index among offshore oil industry workers: cross-sectional and longitudinal findings. Occup Med 2003;53:213-21.

113 Stewart A, Ledingham R, Furnace G, et al. The ability of UK offshore workers of different body size and shape to egress through a restricted window space. Appl Ergon 2016;55:226-33.

114 Stewart AD, Ledingham RL, Furnace G, et al. Shape change and obesity prevalence among male UK offshore workers after 30 years: new insight from a 3D scanning study. Am J Hum Biol 2017;29:1-7.

115 Miller P, Brook L, Stomski NJ, et al. Suicide risk and social support in Australian resource sector employees: a cross-sectional study. $J$ Community Psychol 2019;47:652-62.

116 Cantwell LB, Henao OL, Hoekstra RM, et al. The effect of different recall periods on estimates of acute gastroenteritis in the United States, FoodNet population survey 2006-2007. Foodborne Pathog Dis 2010;7:1225-8.

117 Zhao Y, Richardson A, Poyser C, et al. Shift work and mental health: a systematic review and meta-analysis. Int Arch Occup Environ Health 2019;92:763-93.

118 Costa G. The problem: shiftwork. Chronobiol Int 1997:14:89-98.

119 Vojnovic P, Michelson G, Jackson D. Adjustment, well-being and help-seeking among Australian FIFO mining employees. $A b /$ 2014:40:242-61.

120 Rhéaume A, Mullen J. The impact of long work hours and shift work on cognitive errors in nurses. J Nurs Manag 2018;26:26-32.

121 Kecklund G, Axelsson J. Health consequences of shift work and insufficient sleep. BMJ 2016;355:i5210-3

122 Ferguson SA, Paech GM, Dorrian J, et al. Performance on a simple response time task: is sleep or work more important for miners? Appl Ergon 2011;42:210-3.

123 Wright KP, Bogan RK, Wyatt JK. Shift work and the assessment and management of shift work disorder (SWD). Sleep Med Rev 2013;17:41-54.

124 McKenna $\mathrm{H}$, Wilkes M. Optimising sleep for night shifts. BMJ 2018;360:j5637-5.

125 Tucker PE, Cohen PA, Bulsara MK, et al. Fatigue and training of obstetrics and gynaecology trainees in Australia and New Zealand. Aust N Z J Obstet Gynaecol 2017;57:502-7.

126 Shen J, Botly LCP, Chung SA, et al. Fatigue and shift work. J Sleep Res 2006;15:1-5.

127 World Health Organization. Alcohol. key facts, 2019. Available: www.who.int/news-room/fact-sheets/detail/alcohol [Accessed 20 Nov 2020].

128 Collinson DL. "Shift-ing Lives": Work-Home Pressures in the North Sea Oil Industry*. Can Rev Sociol Anthropol 1998;35:301-24.

129 Wilsnack RW, Wilsnack SC, Gmel G, et al. Gender differences in binge drinking. Alcohol Res 2018;39:57-76.

130 Todd M. Daily processes in stress and smoking: effects of negative events, nicotine dependence, and gender. Psychol Addict Behav 2004;18:31-9.

131 World Health Organization. Tobacco. key facts, 2021. Available: https://www.who.int/news-room/fact-sheets/detail/tobacco [Accessed 20 Nov 2020].

132 Cahill K, Lancaster T, Cochrane Tobacco Addiction Group. Workplace interventions for smoking cessation. Cochrane Database Syst Rev 2014;31.

133 Shrestha A, Pyakurel P, Shrestha A, et al. Facilitators and barriers to healthy eating in a worksite cafeteria: a qualitative study from Nepal. Heart Asia 2017;9:e010956.

134 Leedo E, Beck AM, Astrup A, et al. The effectiveness of healthy meals at work on reaction time, mood and dietary intake: a randomised cross-over study in daytime and shift workers at an university hospital. Br J Nutr 2017;118:121-9.

135 World Health Organization. Healthy diet. key facts, 2020. Available: https://www.who.int/news-room/fact-sheets/detail/healthy-diet [Accessed 20 Nov 2020].

136 Bakker AB, Demerouti E. The job Demands-Resources model: state of the art. J Manag Psychol 2007;22:309-28.

137 Neimann Rasmussen L, Montgomery P. The prevalence of and factors associated with inclusion of non-English language studies in Campbell systematic reviews: a survey and metaepidemiological study. Syst Rev 2018;7:1-12 